\title{
富电子炔烃和羧酸的加成反应研究进展
}

\author{
曾林伟＼cjkstart崔孙良* \\ (浙江大学药学院 药物发现与设计研究所 杭州 310058)
}

\begin{abstract}
摘要 富电子炔烃, 顾名思义, 就是碳碳参键与一个富电子原子或基团连接, 使得参键上的电子云分布改变, 从而具 有活泼的化学反应活性. 富电子炔烃在有机合成中扮演了十分重要的角色，可作为合成模块用于各类新型有机反应的 开发. 其中, 富电子炔烃和羧酸的氢一酰氧化加成反应是富电子炔烃化学的重要部分, 近年来也有了系统的研究. 本综 述对富电子炔烃与羧酸的加成反应及其合成应用进行了详细总结, 并对该领域进行了展望.
\end{abstract}

关键词 富电子炔烃; 羧酸; 加成反应; 氢一酰氧化

\section{Recent Progress in the Addition Reaction of Electron-Rich Alkynes and Carboxylic Acids}

\author{
Zeng, Linwei Cui, Sunliang* \\ (Institute of Drug Discovery and Design, College of Pharmaceutical Sciences, Zhejiang University, Hangzhou 310058)
}

\begin{abstract}
Electron-rich alkynes, in which an electron-donating atom or group is attached to the triple bond, have been widely used as versatile building blocks in organic synthesis, due to their unique chemical reactivity. As an important part of electron-rich alkyne chemistry, the addition reaction between electron-rich alkynes and carboxylic acids received considerable attention these years, and various investigations and advances have been reported. The progress of addition reactions between electron-rich alkynes and carboxylic acids is summarized, and the future perspective is prospected.

Keywords electron-rich alkyne; carboxylic acid; addition reaction; hydro-acyloxylation
\end{abstract}

富电子炔烃(electron-rich alkynes)是一类碳碳参键 与一个供电子原子或供电子基团直接连接的炔烃, 这些 炔烃的结构以及共振如图 1A 所示, 这种共振使富电子 炔烃呈现出亲电和亲核的双重反应活性. 常见的炔酰胺 (ynamides)、炔醚(ynol ethers)、炔硫醚(alkynyl thioethers)、炔胺(ynamines)和炔基三氮烯(1-alkynyltriazenes)等都属于富电子炔烃(图 1B). 这些富电子炔烃 易于制备 ${ }^{[1]}$, 在杂环化合物合成 ${ }^{[2]}$ 、自由基化学 ${ }^{[3]}$ 、卡宾 卡拜化学 ${ }^{[4]}$ 、有机环加成和重排反应 ${ }^{[5]}$ 以及天然产物全 合成 ${ }^{[6]}$ 等领域广泛应用.

氢一官能团化加成反应(hydro-functionalization)是富 电子炔烃化学中的一类重要反应, 常见的炔酰胺、炔醚 及炔硫醚等富电子炔烃和氢卤酸 ${ }^{[7]}$ 、膦酸 ${ }^{[8]}$ 、酚或醇 ${ }^{[9]}$ 、 氨基化合物 ${ }^{[10]}$ 等质子性试剂都可以发生该类加成反应 实现氢一官能团化(Scheme 1). 其中, 羧酸与非活性炔烃
(A) Electron-rich alkynes:

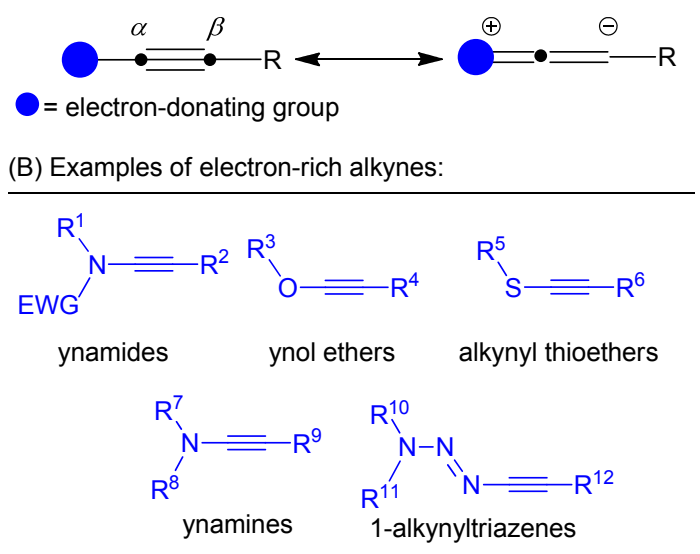

图 1 富电子炔烃及代表性例子

Figure 1 Electron-rich alkynes and representative examples 的加成反应是制备烯醚的重要方法 ${ }^{[1]}$. 近年来, 羧酸和

* Corresponding author. E-mail: slcui@zju.edu.cn

Received March 18, 2020; revised April 29, 2020; published online May 11, 2020.

Project supported by the National Natural Science Foundation of China (No. 21971222) and the Key R\&D Plan of Zhejiang Province (No. 2019C03082).

国家自然科学基金(No. 21971222)、浙江省重点研发计划(No. 2019C03082)资助项目. 
富电子炔烃的加成反应也见诸报道, 其氢一酰氧化 (hydro-acyloxylation)加成产物可以继续作为反应中间 体，参与缩合反应、多组分反应、重排反应及自由基反 应. 本文对富电子炔烃和有机羧酸的加成反应及其合成 应用做一个介绍.

\section{1 炔酰胺和羧酸的加成反应及应用}

炔酰胺因为易于制备、稳定性好, 是富电子炔烃化 学中最受关注的研究对象. 2012 年, Lam 课题组 ${ }^{[12]}$ 首次 报道了炔酰胺和羧酸的氢一酰氧化加成反应, 对各类不 同结构的炔酰胺开展活性篎选, 发现在催化量的醋酸钯 $\left(2 \mathrm{~mol} \%\right.$ ) 存在及 $70{ }^{\circ} \mathrm{C}$ 的反应温度下, 炔酰胺 1 和羧酸 2 在甲苯中可以发生加成反应, 得到 $E$ 型 $\alpha$-酰氧基烯酰胺
( $\alpha$-acyloxy enamides)类化合物 3 (Scheme 2). 该加成反 应的效率较高(收率从中等到 $95 \%$ 以上)并具有良好的区 域选择性和立体选择性. 在底物范围方面, 羧酸涵盖脂 肪羧酸、芳香羧酸、烯酸和炔酸，炔酰胺底物则适用于 噁唑烷酮衍生的炔酰胺和炔磺酰胺等. 不足的是，该加 成反应需要钯金属催化剂.

2015 年，毕锡和课题组 ${ }^{[13]}$ 报道了无催化剂条件下 的炔酰胺和羧酸的氢一酰氧化加成反应. 以甲苯为溶剂 于 $100{ }^{\circ} \mathrm{C}$ 的反应温度下, 炔酰胺 4 和羧酸 5 可以发生加 成反应得到 $E$ 型 $\alpha$-酰氧基烯酰胺 $\mathbf{6}$, 该反应具有良好的 区域选择和立体选择性(Scheme 3, A). 另外, 炔酰胺 7 和醋酸 8 在丙酮和水的混合溶剂中反应, 得到产物 $N$-Ts 酰胺 9 (Scheme 3, B), 其反应历程包括了炔酰胺和醋

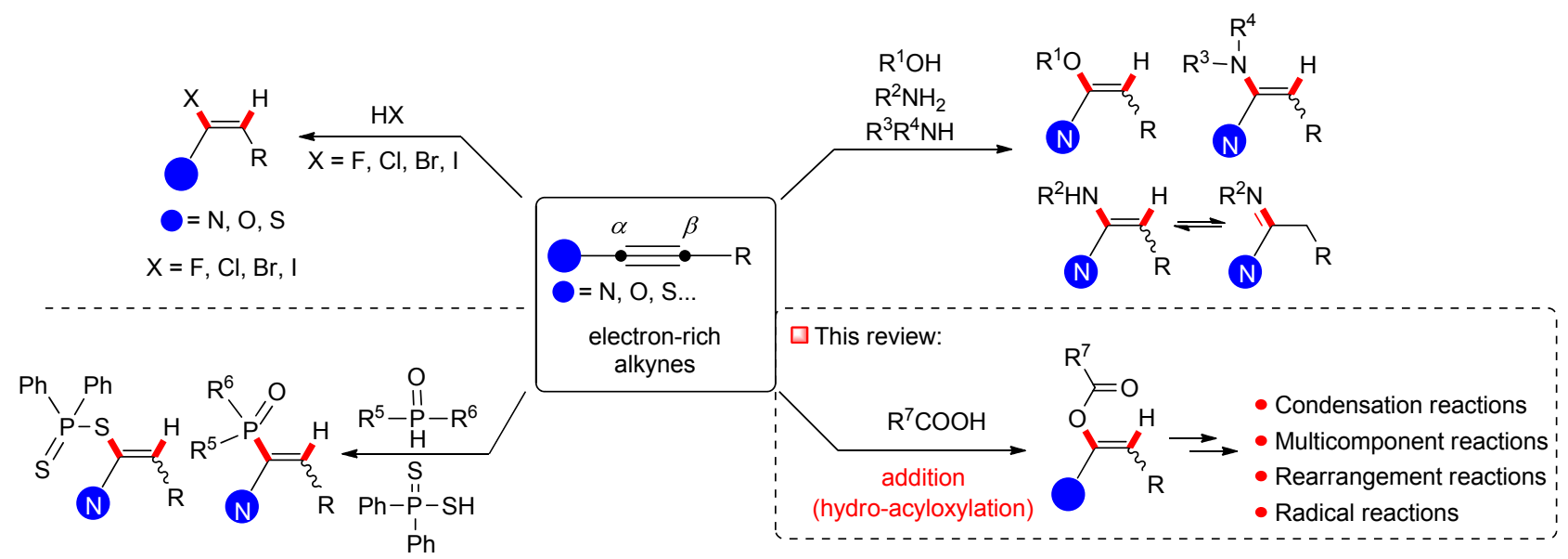

图式 1 富电子炔烃的氢-官能团化反应

Scheme 1 Hydro-functionalization of electron-rich alkynes

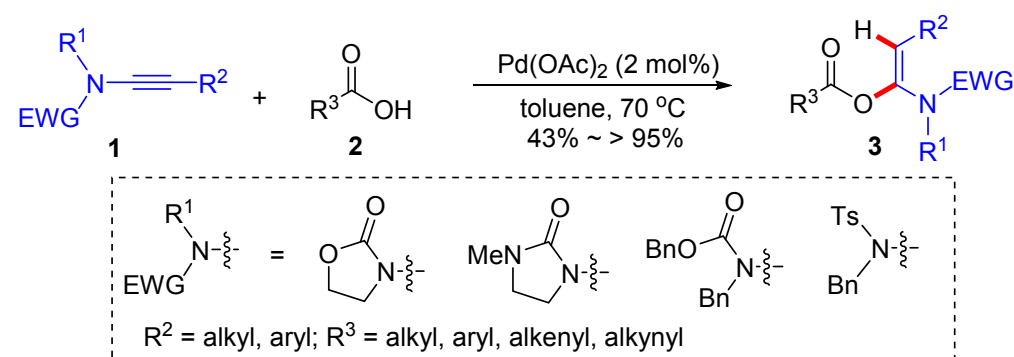<smiles>CC(C)[C@H](N)C(=O)OC(=Cc1ccccc1)N1CCOC1=O</smiles>

$>95 \%$<smiles>O=C(OC(=Cc1cccc([N+](=O)[O-])c1)N1CCOC1=O)c1ccccc1</smiles><smiles>O=C(OC(=Cc1ccccc1)N1CCOC1=O)c1ccccc1</smiles><smiles>O=C(OC(=Cc1ccc(F)cc1)N1CCOC1=O)c1ccccc1</smiles><smiles>O=C(OC(=Cc1ccccc1)N1CCOC1=O)c1ccccc1O</smiles>

$75 \%$<smiles>CC(C)C(=O)O/C(=C/c1ccccc1)N1CCNC1=O</smiles>

$74 \%$<smiles>O=C(/C=C/c1ccccc1)OC(=C(c1ccccc1)c1ccccc1)N1CCOC1=O</smiles>

$80 \%$<smiles>O=C(OC(=Cc1ccccc1)N(Cc1ccccc1)C(=O)Cc1ccccc1)c1ccccc1</smiles><smiles>[3H]N(Cc1ccccc1)/C(=C\c1ccccc1)OC(=O)c1cc(OC)cc(OC)c1</smiles>

图式 2 钯催化炔酰胺和羧酸的加成反应

Scheme 2 Pd-Catalyzed addition reaction between ynamides and carboxylic acids 


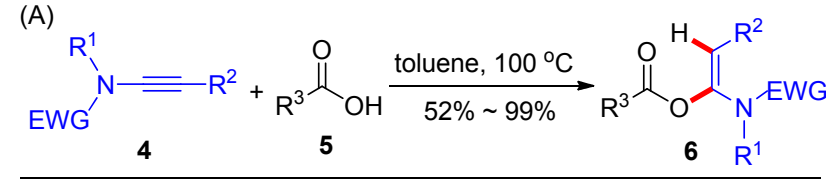

(B)

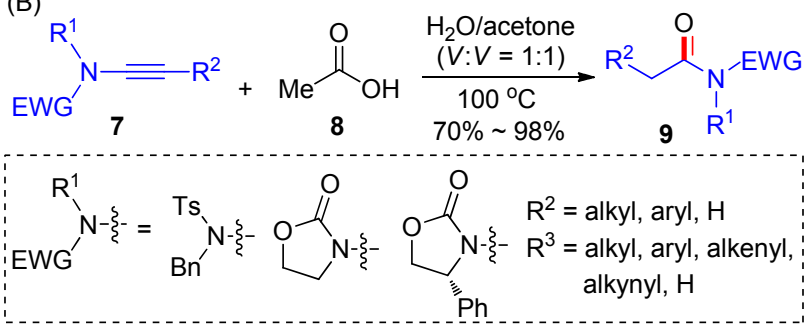

图式 3 炔酰胺和羧酸的无催化加成反应

Scheme 3 Catalyst-free addition reaction between ynamides and carboxylic acids

酸加成反应形成 $\alpha$-乙酰氧基烯酰胺, 随后在高温下发生 水解反应得到产物 9 . 该反应的底物多样性良好, 原子 利用率高且不需要任何催化剂催化, 是一个高效的绿色 合成反应.

2016 年, 赵军锋课题组 ${ }^{[14]}$ 利用炔酰胺在多肽合成 研究领域取得了重要进展. 他们将炔酰胺作为羧酸和胺 的缩合试剂构建酰胺键, 并将该方法应用于氨基酸的缩 合反应中, 发展了一个中性的多肽缩合反应. 首先, 测 试了各类炔酰胺 10 和苯甲酸 (11)的加成反应, 发现炔酰 胺的结构与加成反应活性呈现相关性, 最高效的端炔酰 胺 $10 \mathrm{e}$ 和 $10 \mathrm{f}$ 可以在室温下与苯甲酸发生加成反应生成 12 (Scheme 4, A). 因此, 炔酰胺也被选为缩合试剂开展 了缩合反应的尝试; 结果表明, 羧酸 13 和炔酰胺 $10 \mathrm{e}$
或 $10 \mathrm{f}$ 加成得到的 $\alpha$-酰氧基烯酰胺，可以与一级或二级 胺 14 高效生成酰胺 15. 底物范围方面, 各类脂肪酸、烯 酸、炔酸和芳香酸以及各类一级脂肪胺、二级脂肪胺都 适用于该缩合反应(Scheme 4, B). 在此基础上，该缩合 反应被用于肽类化合物的合成. 以炔酰胺 $10 \mathrm{e}$ 为缩合剂, 各类氨基酸 16 和氨基酸酯 17 可以转化为多肽产物 18 (Scheme 5). 该反应具有效率高及多肽产物不消旋等优 点, 具有重要的应用价值.

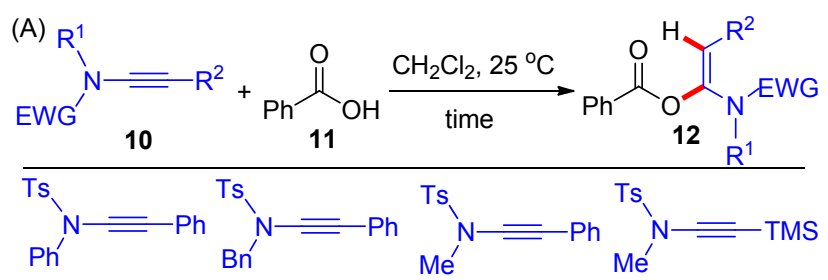

$10 a, 24$ h, $38 \% \quad 10 b, 20$ h, $90 \% \quad 10$ c, 15 h, $93 \% \quad 10$ d, 12 h, $92 \%$
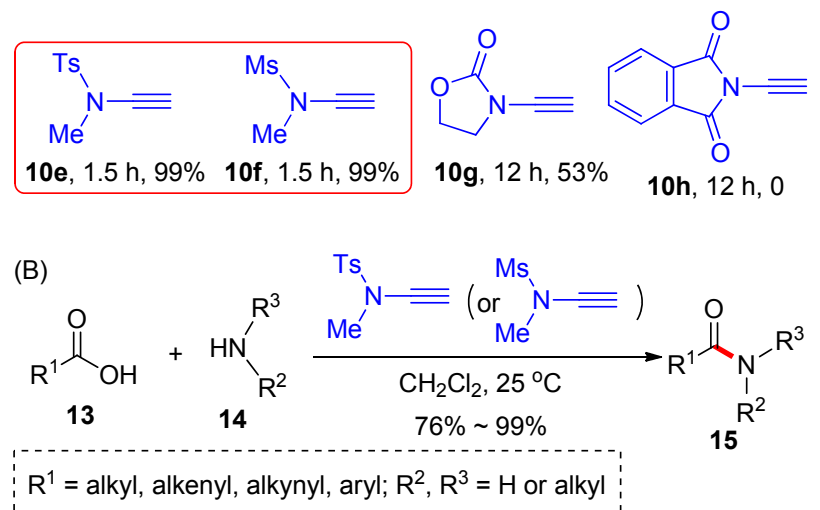

图式 4 炔酰胺介导的酰胺键形成

Scheme 4 Ynamide-mediated construction of amide
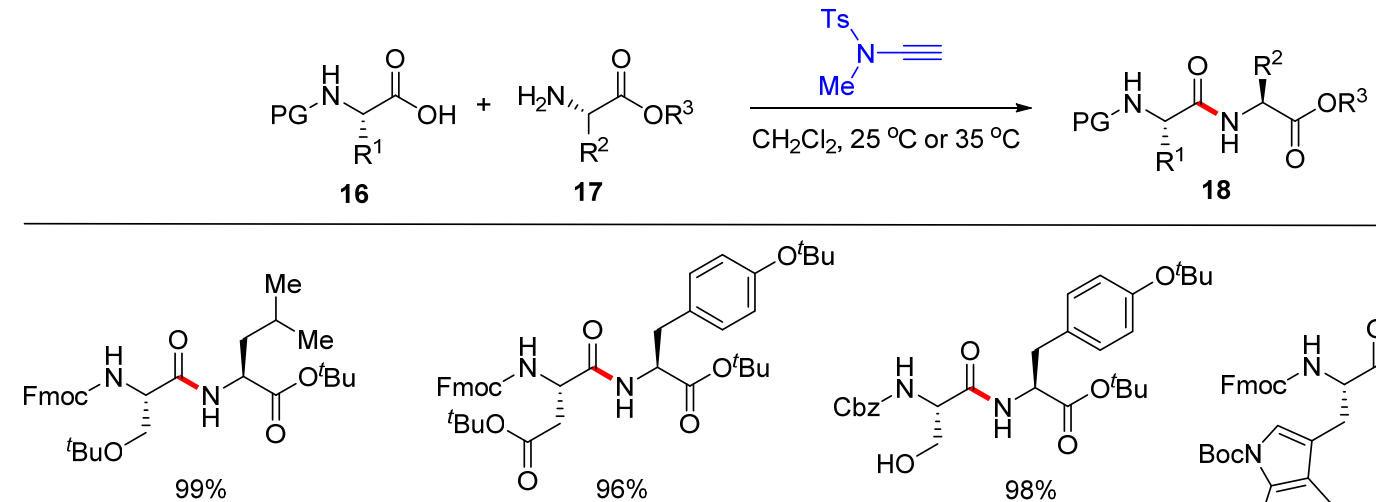<smiles>CCCCOC(=O)C(Cc1ccc(OCCCC)cc1)NC(=O)[C@H](CC(=O)OCCC)NC(=O)OCC</smiles>

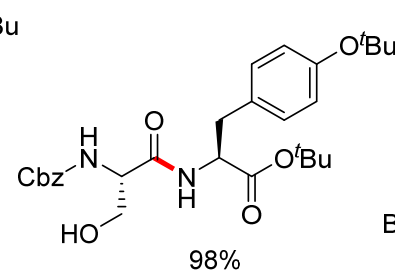<smiles>CCCCOC(=O)N[C@@H](Cc1cn(C(C)(C)C)c2ccccc12)C(=O)NC(Cc1ccc(OCCCC)cc1)C(=O)OCCCC</smiles><smiles>CCCCOC(=O)C(Cc1ccc(OCCCC)cc1)NC(=O)[C@@H](NC(=O)OCc1ccccc1)C(C)(C)C</smiles><smiles>COC(=O)[C@@H]1CCCN1C(=O)[C@H](C)NC(=O)OCc1ccccc1</smiles><smiles>CCCCC(=O)N[C@@H](C(=O)NC(C)(C)C)C(=O)NC(C)(C)O</smiles><smiles>CCCCOC(=O)C(NC(=O)[C@H](CS)NC(F)(F)F)C(C)OCCCC</smiles>

图式 5 炔酰胺实现无消旋构建肽键

Scheme 5 Racemic-free synthesis of peptides using ynamides 
2019 年, 赵军锋课题组 ${ }^{[15]}$ 再次报道了将炔酰胺作 为缩合试剂用于硫肽的合成. 在使硫代氨基酸和炔酰胺 进行加成反应时, 会同时生成 $\alpha$-硫酰氧基烯胺和 $\alpha$-酰硫 基烯胺, 两种产物通过柱层析可以分离. 经过条件优化, 硫代氨基酸 19 和炔酰胺 20 在 $-40{ }^{\circ} \mathrm{C}$ 下于间二甲苯中 发生反应，主要形成 $\alpha$-硫酰氧基烯胺 21 (Scheme 6, A). 将分离出来的 21 和氨基酸酯 $\mathbf{2 3}$ 反应, 在室温下以 $N, N$ 二甲基甲酰胺(DMF)作溶剂, 可以制备硫代酰胺化合物 24 以及副产物 25 (Scheme 6, B). 该工作提供了一条高 效合成硫代酰胺键的路线，具有良好的应用前景.

同时，他们将该方法应用到了亮氨酸脑啡肽衍生物 34 等硫肽类生物活性分子的全合成(Scheme 7, A): 首 先, 荡甲氧羰基(Fmoc)保护的硫代苯丙氨酸与炔酰胺加 成以 $65 \%$ 的分离产率得到化合物 $\mathbf{2 6}$, 随后 $\mathbf{2 6}$ 与亮氨酸 叔丁酯(27)进行缩合反应构建酰胺键, 并用二乙胺脱去 Fmoc 保护基得到二肽化合物 28; 二肽 28 与 Fmoc-甘氨 酸和炔酰胺的加成产物 29 缩合, 用二乙胺脱去 Fmoc 保 护基后得到了三肽化合物 $\mathbf{3 0}$; 甘氨酸叔丁酯(31) 与 $\alpha$-硫 酰氧基烯胺 32 缩合后脱去叔丁基得到二肽 33 ; 最后, 将得到的 33 与 30 使用炔酰胺进行缩合反应即可得到目
标化合物 34. 类似的, 细菌 DNA 促旋酶抑制剂 Closthioamide (40)的全合成也按照该策略进行 (Scheme 7, B): Fmoc 保护的 $\beta$-硫代丙氨酸与炔酰胺发生加成反应 制备 $\alpha$-硫代酰氧基烯胺 35; 随后，两分子 35 与丙二胺 (36)进行缩合得到化合物 37; 脱去 Fmoc 保护基后与两 分子 35 再进行一次缩合反应可以得到化合物 $\mathbf{3 8}$, 这两 步的收率达到 85\%; 脱去化合物 $\mathbf{3 8}$ 上的 Fmoc 保护基, 并与 $\alpha$-酰氧基烯胺 39 进行再次缩合, 然后用四丁基氟 化铵(TBAF)进行羟基脱保护, 即得到目标产物 40. 在 此过程中, 炔酰胺作为缩合剂构建酰胺键, 具有高效和 无消旋化等优点, 是肽类和硫肽类化合物合成中新的重 要策略.

近期, 在炔酰胺介导的酰胺键构建的基础上, 赵军 锋课题组 ${ }^{[16]}$ 又成功发展了炔酰胺介导的酯键形成反应. 羧酸 41 和炔酰胺 42 在二氯甲烷中完成加成反应形成 $\alpha$ 烷氧基烯酰胺 43 后，移去二氯甲烷并加入乙腈; 随后， 往体系中加入羟基化合物 44 和催化量的碱, 在室温下 就可以高效地实现酯化反应得到产物 $\mathbf{4 5}$ (Scheme 8, A). 该反应的羒酸底物可以涵盖脂肪羧酸、烯酸、炔酸和芳 香酸; 羟基化合物方面，酚类和醇类化合物均可以参与

(A)

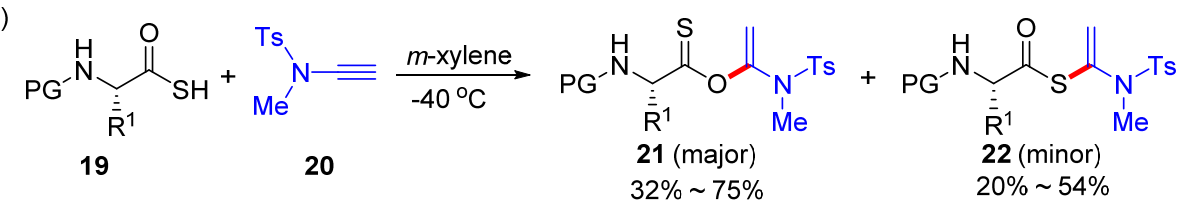

(B)
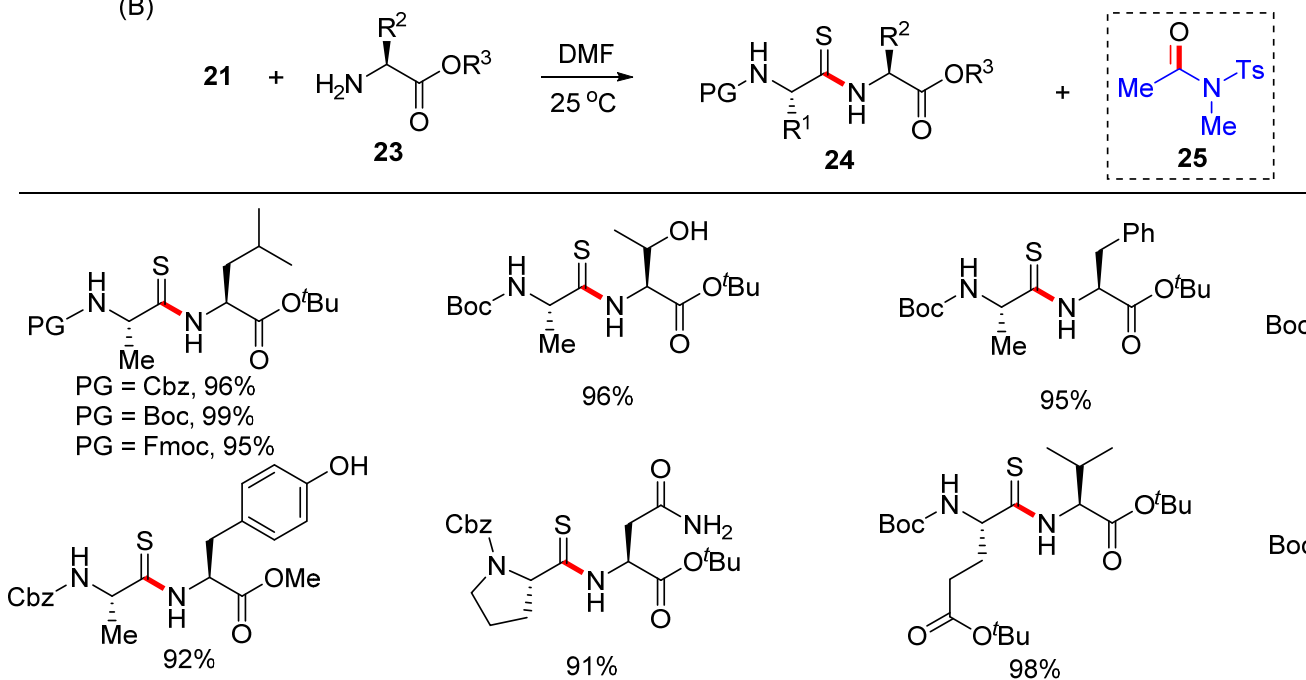<smiles>CC(C)(C)OC(=O)NC(C(=O)O)C(=O)NC(CC(N)=O)C(=O)O</smiles><smiles>CC(C)C(=O)C(NC(=S)[C@H](CCC(N)=O)NC(=O)[O-])C(C)O</smiles><smiles>CN(C)C(=O)C(CC(N)=O)NC(=S)C1CCCN1</smiles>

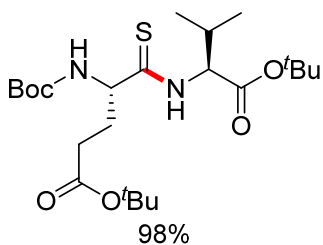<smiles>COC(=O)C(CC(=O)Nc1ccccc1)C(=S)NC(CCCCNC(=O)O)C(=O)O</smiles><smiles>CCC(C)C(NC(=S)C(CCCNC(=NC)NC(=O)c1ccccc1)NC(=O)OCc1ccccc1)C(=O)OC</smiles><smiles>COC(=O)C(NC(=S)[C@H](Cc1cc2ccccc2n1C(=O)O)NC(=O)c1ccccc1)C(=O)O</smiles>

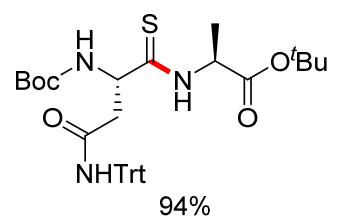

图式 6 炔酰胺实现无消旋构建硫肽键

Scheme 6 Racemic-free construction of thiopeptides using ynamides 
(A)<smiles>C=C(OC(=S)[C@@H](Cc1ccccc1)NC(F)(F)F)N([13CH3])[13CH3]</smiles>

(1) DMF, $0{ }^{\circ} \mathrm{C}, 93 \%$

(2) $\mathrm{Et}_{2} \mathrm{~N}, \mathrm{MeOH}, 99 \%$<smiles>CCCCC(NC(=S)C(N)Cc1ccccc1)C(=O)OCC</smiles>

26, $65 \%$

27

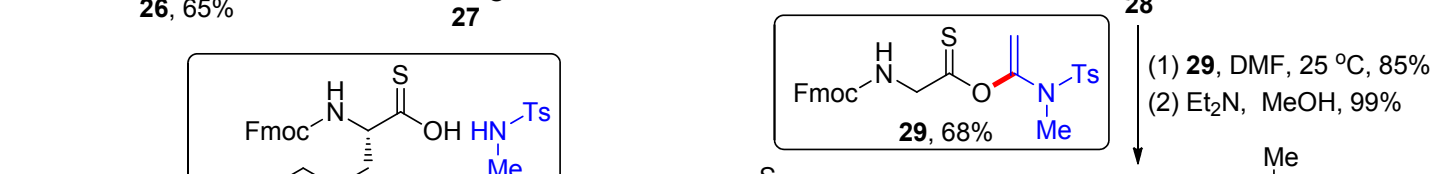

28

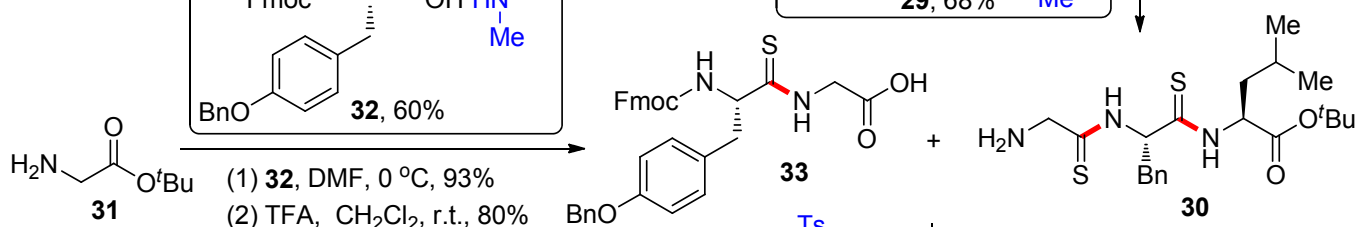

$\underset{\mathrm{Me}^{\prime}}{\mathrm{Ts}}=\downarrow \mathrm{CH}_{2} \mathrm{Cl}_{2}, 25^{\circ} \mathrm{C}, 84 \%$<smiles>[M]C(C)CC(NC(=S)C(Cc1ccccc1)NC(=S)NC(=O)CNC(=S)[C@H](Cc1ccc(OCc2ccccc2)cc1)NC(F)(F)F)C(=O)OCCCC</smiles>

(B)<smiles>C=C(OC(=S)CCNC(F)F)N([13CH3])[14CH3]</smiles>
$65 \%$ yield<smiles>CCCCCCCCCCN</smiles>
$98 \%$

(1) $\mathrm{Et}_{2} \mathrm{NH}, \mathrm{MeOH}$, r.t., $1.5 \mathrm{~h}$ (2) $35, \mathrm{CH}_{2} \mathrm{Cl}_{2} / \mathrm{MeOH}(V: V=5: 1)$, r.t., 2 h

$85 \%$<smiles>O=C(CF)NCCC(=S)NCCC(=S)NCCCNC(=S)CCNC(=S)CCNC(F)F</smiles>

(1) $\mathrm{Et}_{2} \mathrm{NH}, \mathrm{MeOH}$, r..t., $1.5 \mathrm{~h}$

(2) 39, $\mathrm{CH}_{2} \mathrm{Cl}_{2} / \mathrm{MeOH}(\mathrm{V}: \mathrm{V}=5: 1)$, r.t., $2 \mathrm{~h}$ (3) TBAF $67 \%$ for three steps<smiles>Oc1ccc(C(=S)NCCC(=S)NCCC(=S)NCCCNC(=S)CCNC(=S)CCNC(=S)c2ccc(O)cc2)cc1</smiles>

图式 7 炔酰胺实现无消旋构建硫肽键的应用

Scheme 7 Synthetic application of racemic-free synthesis of thiopeptides using ynamides

该酯化反应, 体现出良好的普适性. 需要注意的是, 当 使用酚类作为反应底物时, 三乙胺 (TEA)或者 $N, N$-二异 丙基乙胺(DIPEA)可以有效催化该酯化反应; 而对于醇 类底物, 碱则需要调整为 $N, N, N^{\prime}, N^{\prime}$-四甲基-1,3-丙二胺 (TMPDA). 同时, 该研究组 ${ }^{[17]}$ 成功开发了炔酰胺介导的 大环内酯化反应. 他们将差基羧酸 46 与炔酰胺 42 在二 氯甲烷中进行加成反应，分离得到 $\alpha$-酰氧基烯酰胺 47; 随后在对甲苯磺酸水合物 $\left(\mathrm{TsOH} \cdot \mathrm{H}_{2} \mathrm{O}\right)$ 的催化下, 以低 反应浓度于二氯甲烷中成功实现了分子内的缩合反应, 得到了一系列的七元环到十七元环的大环内酯产物 $\mathbf{4 8}$ (Scheme 8, B).
该酯键形成反应具有条件温和、产率高和产物无消 旋化等特点，是一种具有良好应用潜力的酯键合成方 法. 尤其是炔酰胺介导的大环内酯化反应的合成价值, 可以在活性大环内酯分子的全合成中得到展现. 例如, 该反应可以用于抗真菌类环肽类似物 Dehydroxy LIF04a (53)的快速全合成(Scheme 9): 首先，肽类化合 物 49 利用炔酰胺介导的大环内酯化可以高效地制备十 九元环产物 50, 两步的反应收率分别可以达到 $97 \%$ 和 95\%; 随后，利用氢化反应脱去 $\mathbf{5 0}$ 上的 $\mathrm{Cbz}$ 保护基，以 $73 \%$ 的收率得到化合物 $51 ; 51$ 与羧酸 52 先后经过缩合 反应和脱去 Boc 保护基即可得到目标化合物 53. 此路线 


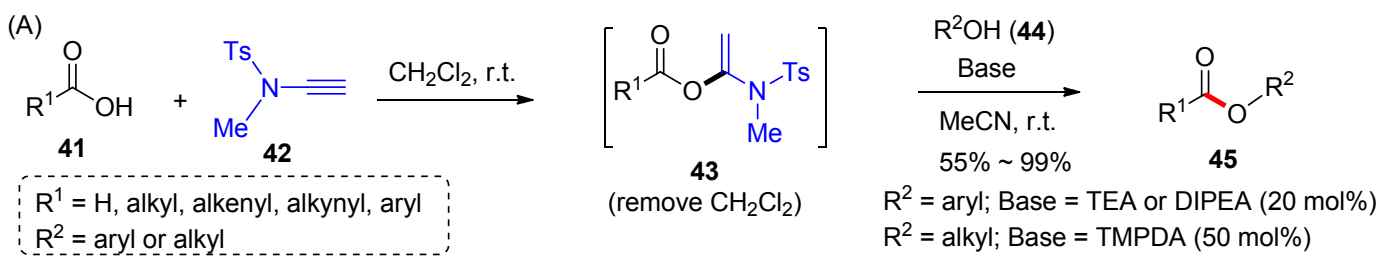

(B)

म19-

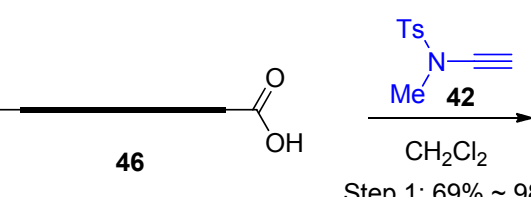

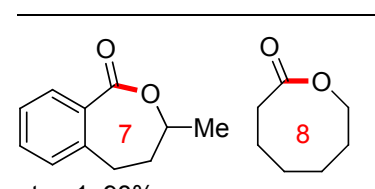

step 1: $98 \%$ step 2: $98 \%$<smiles>O=C1CCCC/C=C\CCCCO1</smiles>

step 1: $76 \%$ step 2: $76 \%$<smiles>CCOC(=O)Cc1ccccc1CCCOCCOCCOCCOC</smiles>

step 1: $75 \%$ step 2: $91 \%$ step 1: $90 \%$ step 2: $85 \%$

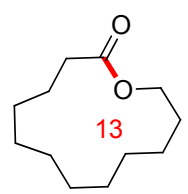

step 1: $87 \%$ step 2: $89 \%$ Step 1: $69 \%$ 98\%
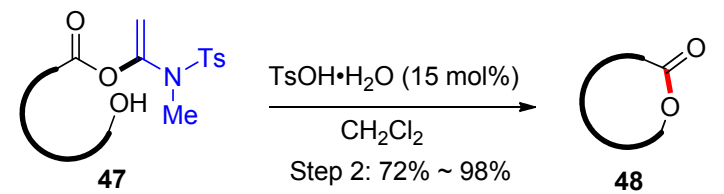

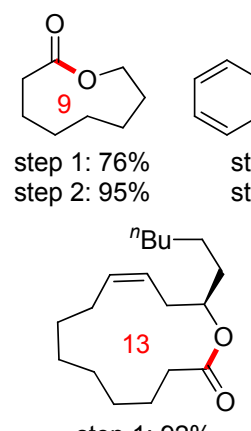

step 1: $92 \%$ step 2: $91 \%$<smiles>CCCOC(=O)OCCCCCCCCCCCC(=O)N[C@@H](CC(C)C)C(=O)O</smiles>

step 1: $87 \%$

step 2: $81 \%$, ee $98 \%$<smiles>O=C1CCCCCCCCCO1</smiles>

step 1: $98 \%$ step 2: $91 \%$<smiles>O=C1C=CCCCCCCCO1</smiles>

step 1: $98 \%$ step 2: $91 \%$

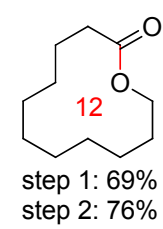<smiles>Cc1ccccc1CCCOCCOCCOCCOC(=O)c1ccccc1</smiles><smiles></smiles>

step 1: $88 \%$ step 2: $72 \%$, ee $98 \%$ step 1: $94 \%$ step 2: $93 \%$

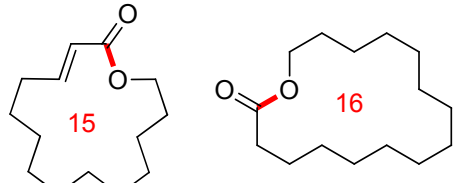

step 1: $90 \%$ step 2: $92 \%$ step 1: $75 \%$ step 2: $98 \%$<smiles>CC(C)(C)CC[C@H](CCCCCCCCCCC(=O)N[C@@H](Cc1ccccc1)C(=O)O)OC(C)(C)C</smiles>

step 1: $89 \%$ step 2: $93 \%, d r>99: 1$

图式 8 炔酰胺介导的酯键形成及大环内酯化

Scheme 8 Ynamide-mediated esterification and macrolactonization<smiles>CC(C)C(=O)NC(C(=O)NC(C(=O)NC(CC(=O)O)C(=O)NCC(=O)O)C(=O)NC(C(C)C)C(C)C)C(C)C</smiles>

(1) ynamide $42, \mathrm{CH}_{2} \mathrm{Cl}_{2}$, r.t. (2) $\mathrm{TsOH} \cdot \mathrm{H}_{2} \mathrm{O}, \mathrm{CH}_{2} \mathrm{Cl}_{2}$, r.t. step 1: $97 \%$ step 2: $95 \%$

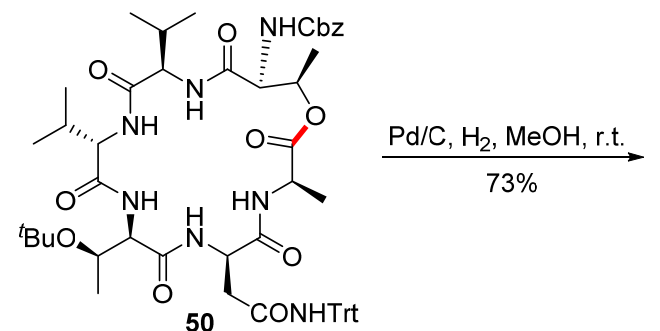

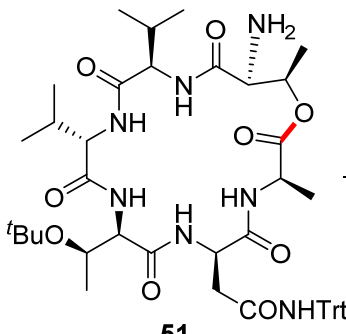<smiles>NC(=NC=NCC(=O)O)NC(=O)O</smiles>

(1) HATU, DIPEA, DMF

(2) $V\left(\right.$ TFA): $V\left(\mathrm{CH}_{2} \mathrm{Cl}_{2}\right): V\left(\mathrm{H}_{2} \mathrm{O}\right)=90: 5: 5$ $60 \%$ over two steps $40 \%$ overall yield

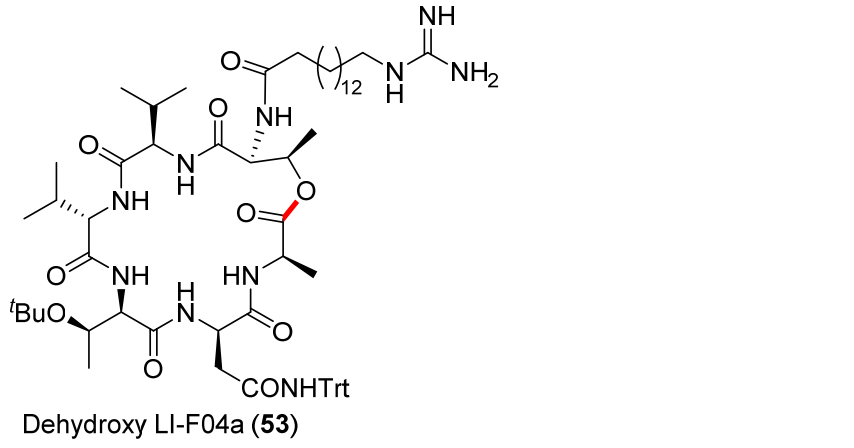

图式 9 炔酰胺介导大环内酯化的合成应用

Scheme 9 Synthetic application of ynamide-mediated macrolactonization 
仅需要五步反应就能以 $40 \%$ 的总收率得到结构复杂的 生物活性分子. 该工作完善了炔酰胺作为缩合试剂在有 机合成中的应用. 在酰胺键和酯键的构建方面, 赵军锋 课题组将炔酰胺推向了举足轻重的地位.

除了用于酰胺键和酯键的构建, 炔酰胺和羧酸的 氢一酰氧化加成反应还可应用于多组分反应. 2017 年, 我们课题组 ${ }^{[18]}$ 通过 “亲核/亲电双重活性设计”, 发现炔 酰胺的互变异构呈现了 “亲核/亲电双重活性”, 该性质 与异腈具有相似性, 并基于该设计揭示了炔胺的 C2 合 成模块性质, 开发了一个新型的炔胺、羧酸、醛、胺的 类 Ugi 四组分反应, 合成了 $\beta$-氨基酰胺类化合物(Scheme 10). 反应历程包括了羧酸 54 和炔酰胺 55 的加成反应形 成 $\alpha$-酰氧基烯胺 59, $\alpha$-酰氧基烯胺 59 对三氟化硼乙醚

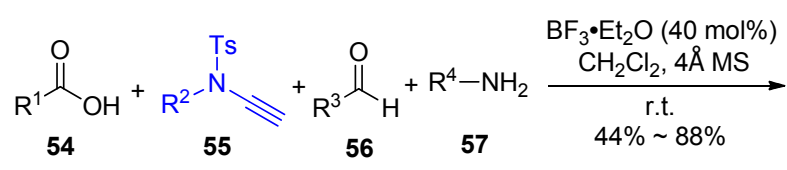

$\mathrm{R}^{1}=$ alkyl, aryl, alkenyl, alkynyl; $\mathrm{R}^{3}=$ aryl, alkenyl, alkynyl, COOEt; $R^{2}=$ alkyl, aryl; $\mathrm{R}^{4}=\operatorname{aryl}$<smiles>[R]C(=O)N([R18])C([R])CC(=O)N([R])[S-]</smiles><smiles>COc1ccc(C(CC(=O)N([13F])[18F])N(C(=O)[Pb])c2ccccc2)cc1</smiles>

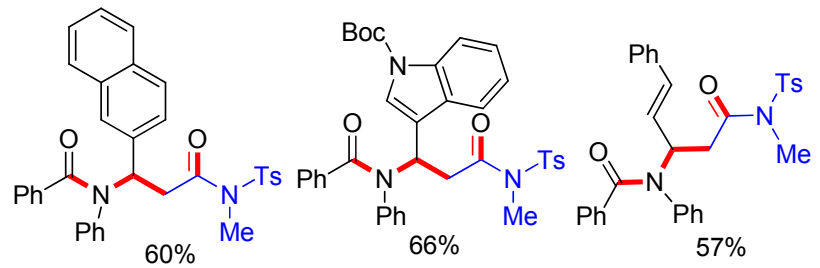

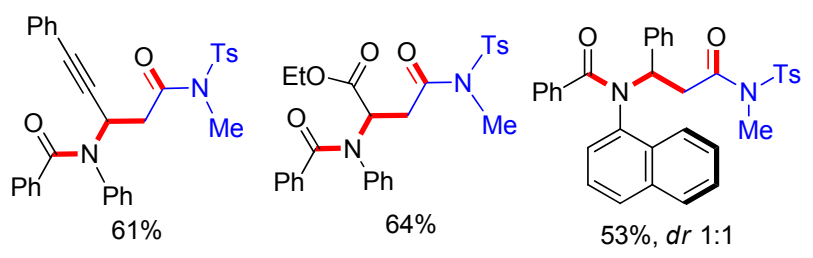

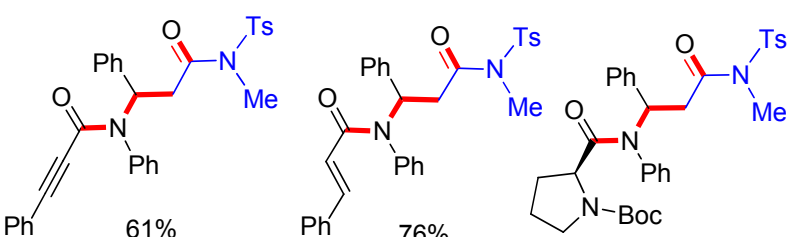

$59 \%, d r 3: 2$

图式 $10 \beta$-氨基酰胺的四组分合成

Scheme 10 Four-component synthesis of $\beta$-amino amides
$\left(\mathrm{BF}_{3} \cdot \mathrm{Et}_{2} \mathrm{O}\right)$ 活化的亚胺鎓离子 60 进行加成得到 $\mathbf{6 1}$, 后发 生 Mumm 重排得到产物 58 (Scheme 11). 反应产物属于 Ugi 反应的同系化产物. 底物范围方面, 各类羧酸、芳香 醛和芳香胺都可以很好地参与该多组分反应. 该工作为 多组分合成模块与反应类型的发展提供了新的视角.

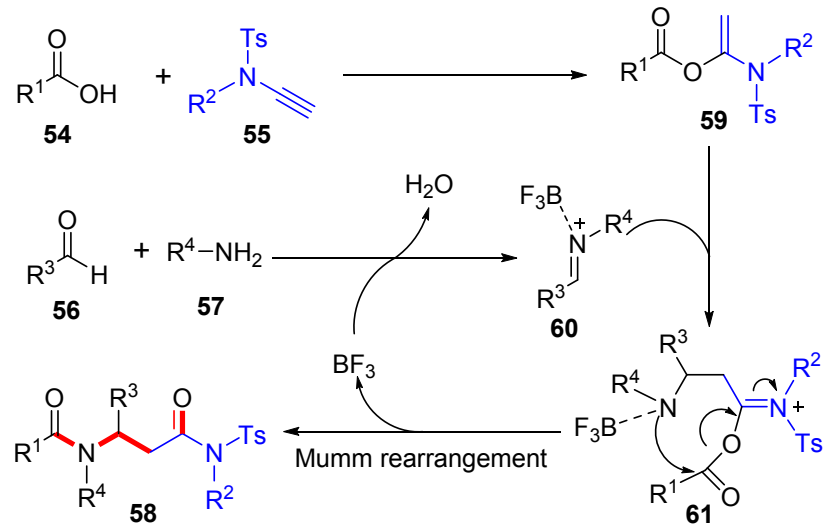

图式 $11 \beta$-氨基酰胺的四组分合成反应机理

Scheme 11 Mechanism of four-component synthesis of $\beta$ amino amides

在此基础上, 我们课题组 ${ }^{[19]}$ 继续利用炔酰胺作为 合成模块, 发展了炔酰胺、羧酸、醛的类 Passerini 三组 分反应合成 $\beta$-酰氧基酰胺类化合物 ( $\beta$-acyloxyamides). 类似地, 羧酸 62 和炔酰胺 63 发生加成反应原位生成 $\alpha$ 酰氧基烯胺，随后与醛 64 和三氟化硼乙醚(40 $\mathrm{mol} \%$ ), 反应可生成 $\beta$-差基酰胺 65 (Scheme 12, A). 底物范围方 面, 各类羧酸、脂肪醛、芳香醛、烯醛和炔醛等都可以 参与该三组分反应. 此外, 我们还将羧酸和醛内置到同 一分子中, 利用邻醛基苯甲酸(66)和炔酰胺 67 的反应, 实现了苯并呋喃酮类化合物 68 的合成(Scheme 12, B); 从而拓展了炔酰胺与羧酸的氢-酰氧化反应在多组分反 应领域的应用.

除了醛、亚胺等常见的亲电试剂, 我们还进一步引 入各类亲电试剂, 开发了各类基于炔酰胺的新型多组分 反应. 比如, 邻亚甲基苯醌类化合物(ortho-quinone methides) 是有机化学和化学生物中一类常见中间体 ${ }^{[20]}$, 并 具有较高的化学反应活性. 我们 ${ }^{[21]}$ 认为邻亚甲基苯醌 类化合物可以作为亲电试剂应用于多组分反应: 利用羧 酸和炔酰胺加成反应生成的 $\alpha$-酰氧基烯酰胺, 对原位生 成的邻醌亚甲基化合物进行 1,4-加成/酯化反应，实现多 组分串联反应. 通过条件优化发现, 加入化学计量的三 氟化硼乙醚可以促进该反应，获得 2-酰氧基苯乙酰胺类 化合物 72 (Scheme 13, A). 可能的反应机理是: 羧酸 69 和炔酰胺 70 完成氢-酰氧化得到 $\alpha$-酰氧基烯酰胺 73; 加 入的邻羟基苄醇 71 在三氟化硼乙醚作用下原位生成邻 亚甲基苯醌化合物 74; 在三氟化嗍乙醚作用下, 73 和 74 发生加成反应后得到 $\mathbf{7 5}$, 然后发生酰基迁移可生成终 
(A)

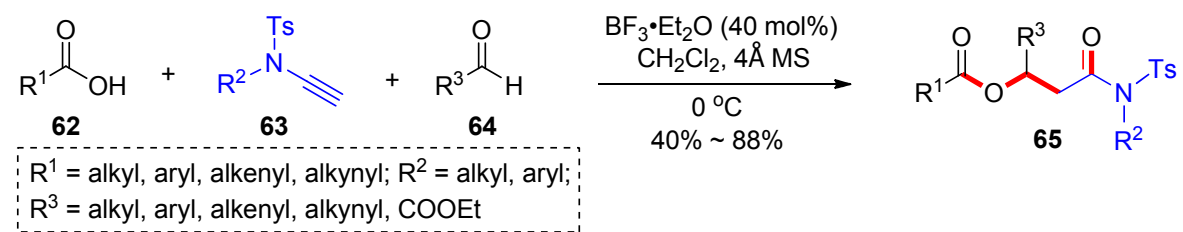<smiles>[Y5]N(C)C(=O)CC(CC(=O)N(C)[13CH3])c1ccc([N+](=O)[O-])cc1</smiles><smiles></smiles><smiles>CN([I-])C(=O)CC1(OC(=O)c2ccc([N+](=O)[O-])cc2)C(=O)N(C)c2c(Br)cccc21</smiles><smiles>C/C=C/C=C/C(=O)OC(CC(=O)N([10SH2])[135I])c1ccc(C#N)cc1</smiles><smiles>CN([13F])C(=O)CC(OC(=O)C#Cc1ccccc1)c1ccc(C#N)cc1</smiles>

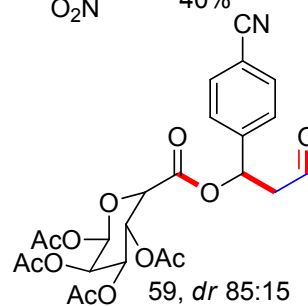<smiles>[3H]N(C(=O)CC(OC(=O)c1ccc([N+](=O)[O-])cc1)c1ccccc1)C(C)c1ccccc1</smiles><smiles>COc1ccccc1N([13CH3])C(=O)C[C@H](OC(=O)c1ccc([N+](=O)[O-])cc1)c1ccccc1</smiles>

(B)<smiles>[R][R1](=O)(OCC)OCCC</smiles>

66

67

$42 \% \sim 87 \%$

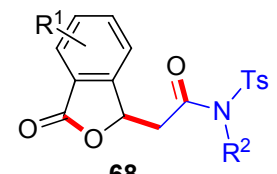

$\mathrm{R}^{1}=\mathrm{Me}, \mathrm{OMe}, \mathrm{F}, \mathrm{Cl} ; \mathrm{R}^{2}=$ alkyl, aryl<smiles>[Y9]N(CC=C)C(=O)CC1OC(=O)c2ccccc21</smiles>

$74 \%$<smiles>[13CH3]N([13CH3])C(=O)C[C@H]1OC(=O)c2c(Cl)cccc21</smiles>

$82 \%$<smiles>CCCOCCN([AlH2])C(=O)CC1OC(=O)c2ccccc21</smiles><smiles>Cc1ccc2c(c1)C(CC(=O)N(C)[13F])OC2=O</smiles><smiles>CC(c1ccccc1)N([13CH3])C(=O)CC1OC(=O)c2ccccc21</smiles>

$73 \%$, dr $3: 1$ $\mathrm{Cl}$<smiles>CN([125I])C(=O)CC1OC(=O)c2cc(Cl)cc(Cl)c21</smiles>

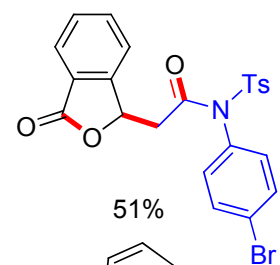<smiles>Cn1c2c(c3ccccc31)C(CC(=O)N([13I])[13I])OC2=O</smiles>

图式 $12 \beta$-羟基酰胺的多组分合成

Scheme 12 Multicomponent synthesis of $\beta$-acyloxyamides

即产物 72 (Scheme 13, B). 三氟化嗍乙醚不仅活化了邻 羟基苄醇释放出活性邻亚甲基苯醌物种, 也在后续的 1,4-加成反应中充当催化剂的角色. 该反应的底物普适 性好, 是一个理性设计的多组分串联反应.

2018 年, 我们课题组 ${ }^{[22]}$ 发展了一个高温促进的氢酰氧化加成串联磺酰基迁移反应. 首先在二甲苯中于 $80{ }^{\circ} \mathrm{C}$ 的反应温度下, 䧳酸 76 和炔酰胺 77 发生加成反应
得到氢-酰氧化产物 78; 升高温度至 $130{ }^{\circ} \mathrm{C}, 78$ 可以转 化为化合物 79 (Scheme 14). 该反应具有较好的合成实 用性，可以放大到克级反应. 比如，当羧酸 76 和炔酰胺 77 在标准条件下完成反应后，加入 KHMDS 可以引发分 子内酰基迁移反应，实现一锅法制备 $\beta$-羰基酰胺类产物 80 (Scheme 15, A); 而酰亚胺产物 81 和乙炔二甲酸二甲 酯(DMAD, 82) 可以在三乙胺作用下发生 $[4+2]$ 环化, 高 


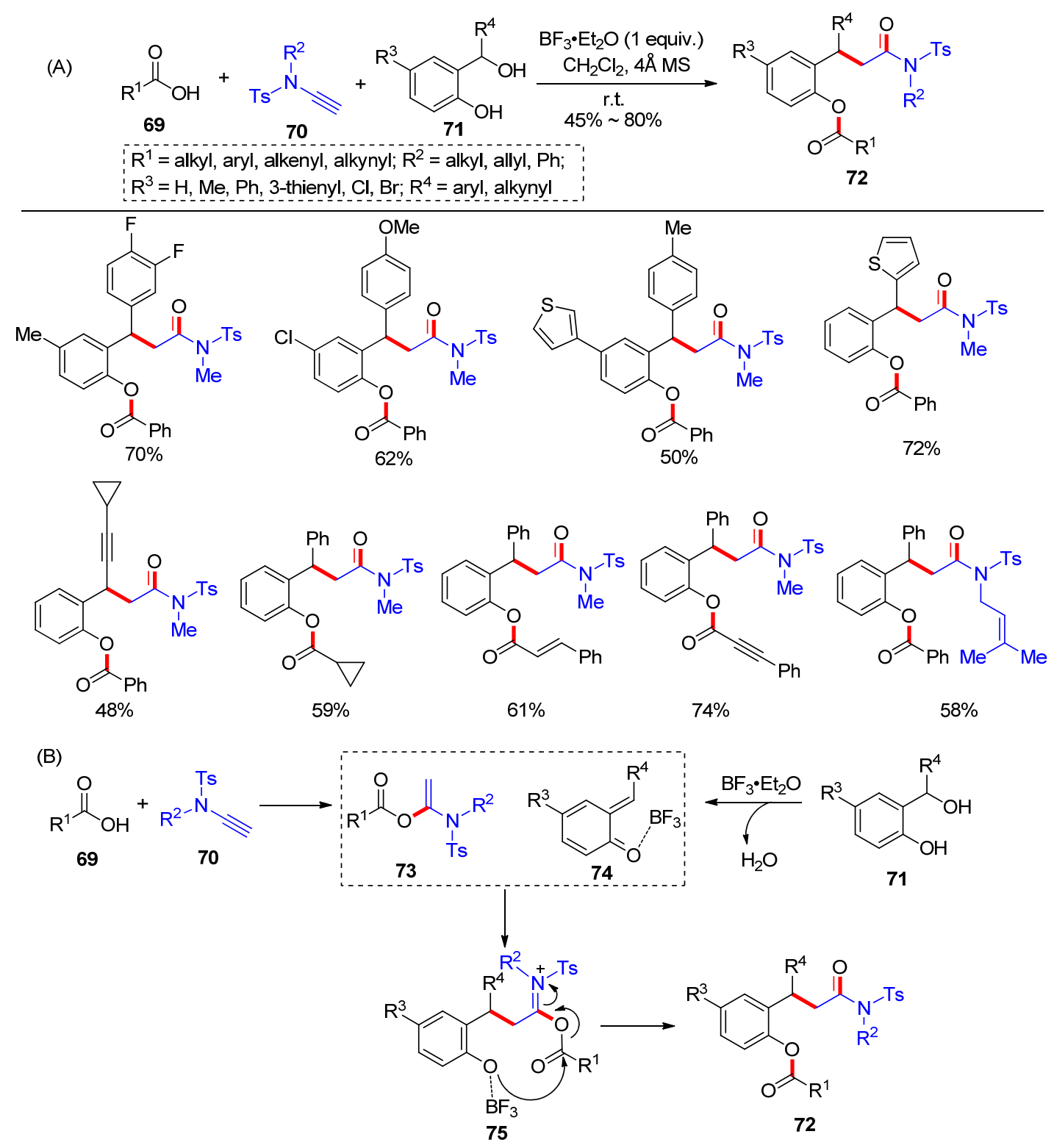

图式 13 炔酰胺、羧酸及邻羟基苠醇参与的三组分反应

Scheme 13 Three-component reaction of ynamides, carboxylic acids and 2-hydroxybenzyl alcohols

效地制备多取代的吡啶酮产物 83 (Scheme 15, B); 另外， 产物 84 可以实现分子内的偶联反应得到环化产物 85 (Scheme 15, C). 该反应历程可能是: 76 和 77 加成形成 氢-酰氧化产物后, 在继续高温下发生碳氮键裂解得到 86 和 87 , 氮负离子 86 异构成碳负离子 88 后, 继续与 87 反应生成中间体 89; 随后, 中间体 89 发生 Mumm 重排 即可得到酰亚胺产物 79 (Scheme 15, D). 该反应基于炔 酰胺和羧酸的加成反应发展了新型一锅法串联反应, 并 开展了合成应用.

在以上的反应研究中, 羧酸显示了良好的普适性. 进一步探索的时候 ${ }^{[23]}$, 我们还发现: 炔酸 90 和炔酰胺 91 在室温下反应可高效合成 $\alpha$-酰氧基烯胺 92; 但随着 温度的升高, 有发生分子内环化得到 $\alpha$-吡喃酮 93 的倾
向. 在大量优化之后，我们得到了最优条件：炔酸 90 和 端炔酰胺在乙腈中于 $90{ }^{\circ} \mathrm{C}$ 下反应，可以得到吡喃酮 93; 当使用内炔酰胺作为底物时, 则需要加入催化量的三氟 甲磺酸银(AgOTf, $10 \mathrm{~mol} \%$ ) 实现该转化(Scheme 16, A). 由于 $\alpha$-吡喃酮是一类优良的 Diels-Alder 反应底物, 我们 继续发展了炔酰胺和炔酸参与的加成反应/串联 DielsAlder 环化. 我们设计了炔基支链取代的炔酰胺 95, 与 炔酸 94 在优化的反应条件下, 实现了炔酸和炔酰胺的 加成反应/串联 Diels-Alder 环化(Scheme 16, B). 该反应 的历程包含了炔酸 94 与炔酰胺 95 形成 $\alpha$-吡喃酮 96 , 高 温下引发了分子内的 Diels-Alder 反应得到了产物 97. 同时，我们发现，得到的 $\alpha$-吡喃酮参与分子间的 DielsAlder 反应难度相对较高，只有使用高活性的乙炔二甲 


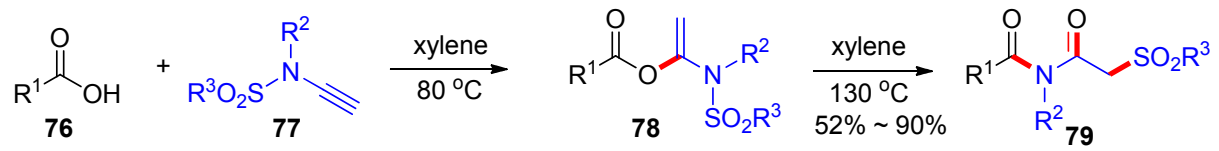

$\mathrm{R}^{1}=$ aryl, alkenyl; $\mathrm{R}^{2}=$ alkyl; $\mathrm{R}^{3}=4$ 4-methylphenyl, phenyl, 2-naphthyl, 2-thienyl, 4-nitrophenyl<smiles>O=C(C[13F])N(Cc1ccccc1)C(=O)c1ccccc1</smiles>

$86 \%$<smiles>O=C(C[13I])N(Cc1ccccc1)C(=O)c1ccco1</smiles>

$77 \%$<smiles>[3H]CC(=O)N(CC[CH]OCC)C(=O)c1ccc(C)cc1</smiles>

$82 \%$<smiles>O=C(C[13F])N(Cc1ccccc1)C(=O)c1ccccc1I</smiles>

$87 \%$<smiles>O=C(C[13F])N(Cc1ccccc1)C(=O)c1cccs1</smiles>

$83 \%$<smiles>O=C(C[As])N(Cc1ccccc1)C(=O)c1ccc2ccccc2c1</smiles>

$55 \%$<smiles>Cn1c(C(=O)N(Cc2ccccc2)C(=O)C[I-])cc2ccccc21</smiles>

$75 \%$<smiles>O=C(C[13S])N(Cc1ccccc1)C(=O)c1ccc(Cl)nc1Cl</smiles>

$68 \%$<smiles>O=C(/C=C/c1ccccc1)N(Cc1ccccc1)C(=O)C[13F]</smiles>

$68 \%$<smiles>Cc1ccc(C(=O)N(C(=O)C[18F])C(C)c2ccccc2)cc1</smiles>
$74 \%$<smiles>C=C(C)CN(C(=O)C[As])C(=O)c1ccc(C)cc1</smiles><smiles>Cc1ccc(C(=O)N(Cc2ccco2)C(=O)C[Te])cc1</smiles><smiles>Cc1ccc(C(=O)N(Cc2ccccc2)C(=O)CS(=O)(=O)c2ccc(C)cc2)cc1</smiles>

图式 14 炔酰胺和炔酸的加成磺酰基迁移反应

Scheme 14 Addition and sulfonyl migration of ynamides and alkynyl acids

(A)

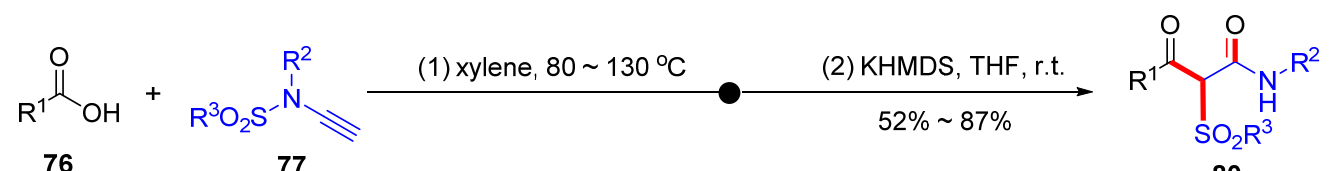

76

77

80

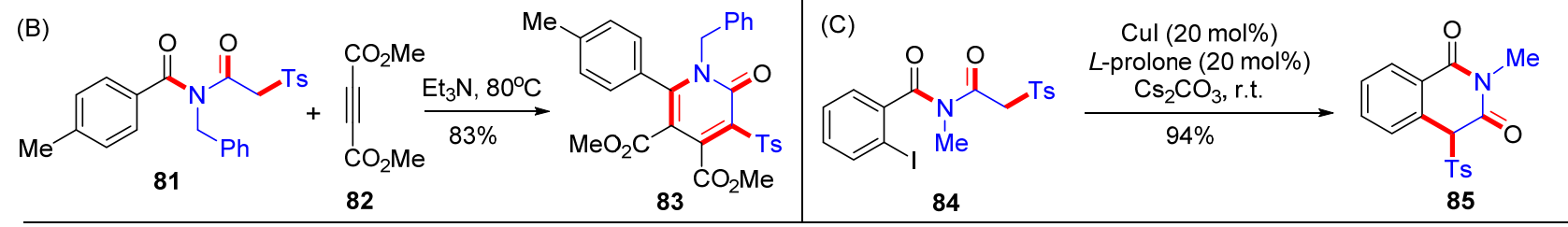

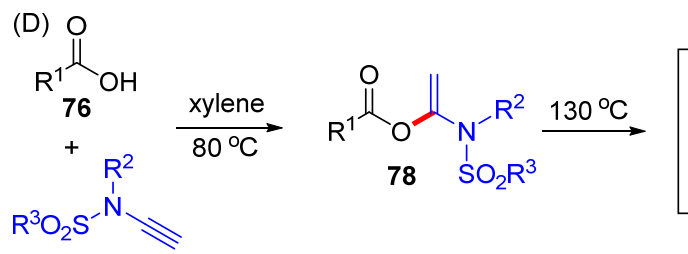

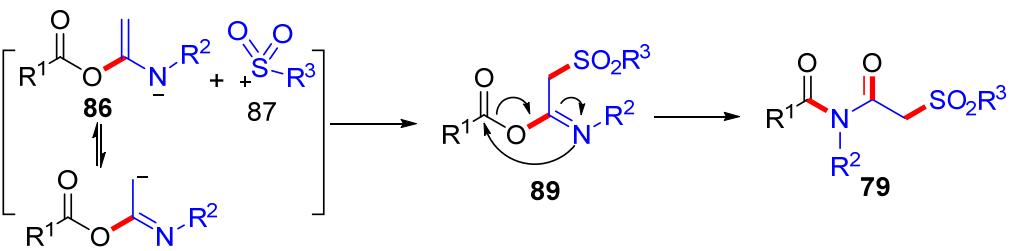

77

88

图式 15 炔酰胺和炔酸的加成磺酰基迁移反应的应用和机理

Scheme 15 Applications and mechanism about addition and sulfonyl migration of ynamides and alkynyl acids

酸二甲酯 $(100)$ 作为底物, 炔酸 98 和端炔酰胺 99 才可以

与之实现加成环合/串联 Diels-Alder 环化, 得到四取代 苯类产物 101 (Scheme 16, C). 该反应以炔酰胺和炔基
羧酸的加成反应为基础, 发展了三类新型有机合成方 法, 为 $\alpha$-吡喃酩、二氢吲哚和多取代苯提供了一条新的 合成路线. 

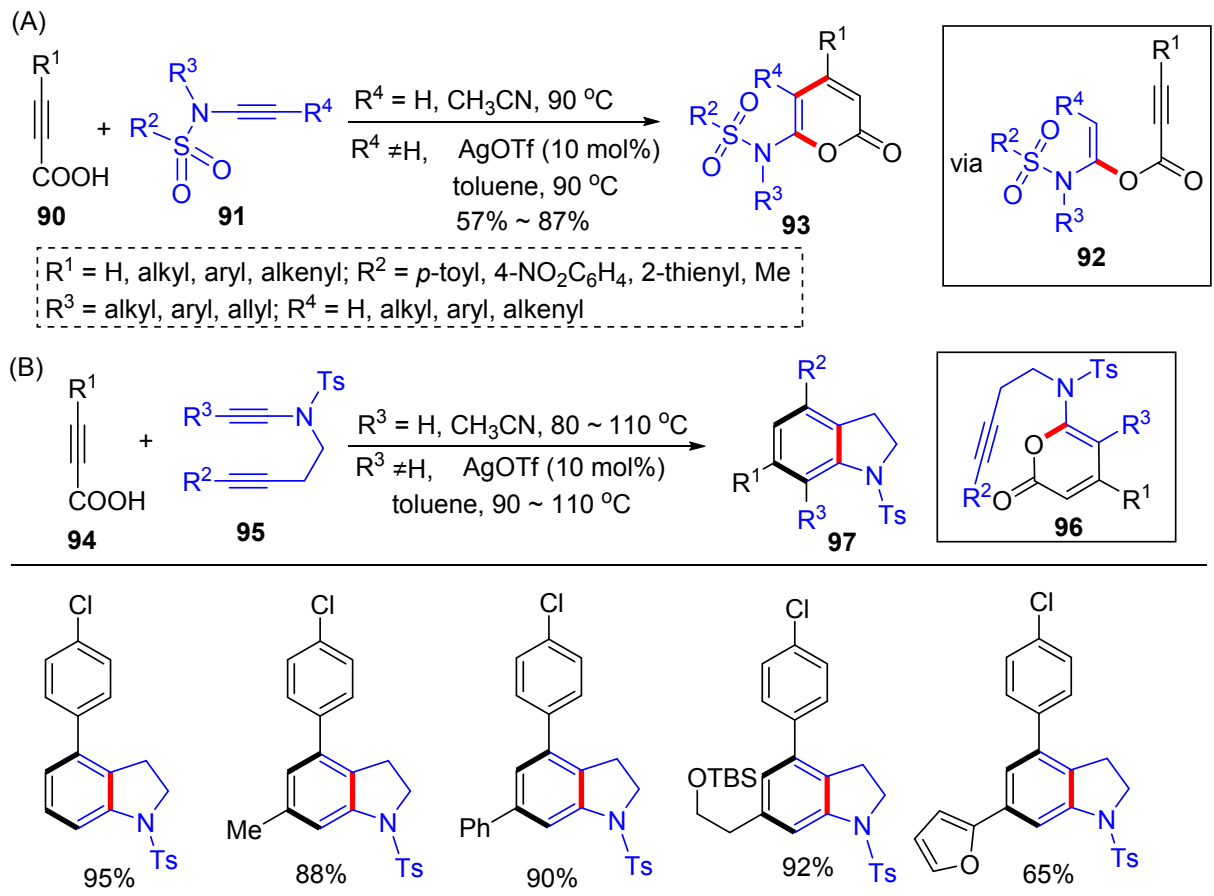<smiles></smiles><smiles>CN1CCc2c(-c3ccc(Cl)cc3)cc(-c3ccco3)cc21</smiles><smiles>C=C(C)c1cc(C)cc2c1CCN2[13CH3]</smiles>
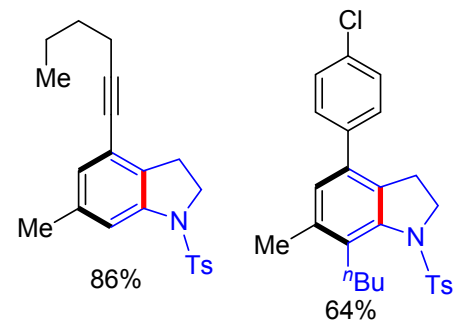<smiles>Cc1cc(C)c(P(=O)([O-])O)c2c1CCN2[13CH3]</smiles>

(C)
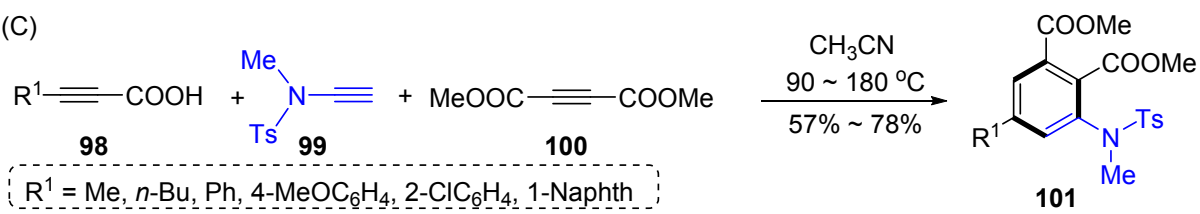

图式 16 炔酰胺和炔酸的加成反应

Scheme 16 Addition reaction between ynamides and alkynyl acids

$\alpha$-酮酸是一类特殊的高活性羧酸, 其在有机化学和 生物化学中都有重要的作用, 常用作脱羧偶联反应和 Minisci 反应的自由基前体等, 并释放出 $\mathrm{CO}_{2}{ }^{[24]}$. 在此过 程中, 我们课题组 ${ }^{[25]}$ 认为 $\alpha$-酮酸具有羧基和亲电性的 酮羰基, 可以开展其与炔酰胺的反应活性探索. 为此, 我们使用 $\alpha$-酮酸 102 和炔酰胺 103 进行尝试, 结果显示, 与羧酸相比, $\alpha$-酮酸和炔酰胺的加成反应速度更快, 反 应产物是 $\beta$-羰基酰亚胺类化合物 105 (Scheme 17, A), 反应过程也释放了大量气体. 我们将释放出的气体通过 气相色谱一热传导检测 (GC-TCD), 确定气体为 CO. 于 是, 我们提出了可能的反应历程: 首先, $\alpha$-酩酸 102 和炔 酰胺 103 发生加成反应原位生成中间体 104; 随后加入 的三氟化硼乙醚活化了 $\alpha$-羰基并诱发了分子内重排, 释 放出 $\mathrm{CO}$ 气体, 得到了产物 105 (Scheme 17, B). 值得一
提的是，在试图分离中间体 104 时，我们发现该类化合 物十分活泼并难以捕获, 因此这个反应只可适用一锅法 操作. 该方法提供了一种简捷高效的 $\beta$-羰基酰亚胺合成 方法.

上述加成反应都是分子间的，而分子内的加成反应 却鲜有报道, 主要是由于该类原料制备困难. 2018 年, Gillaizeau 课题组 ${ }^{[26]}$ 制备了炔酰胺 108, 其结构含有一个 叔丁酯保护的羧基. 在化学计量的三氟乙酸(TFA)的作 用下或者三氟甲磺酸银 $(5 \mathrm{~mol} \%)$ 的催化下，该类炔酰胺 可以发生分子内的环化反应得到氢一酰氧化产物 109 (Scheme 18, A). 此外, 他们还探索了从炔澳 110 出发, 一锅法偶联反应串联分子内环化制备了环状化合物 111 (Scheme 18，B)，该反应适用于六元环和七元环的构建, 是炔酰胺和羧酸的分子内氢一酰氧化加成的唯一例证. 


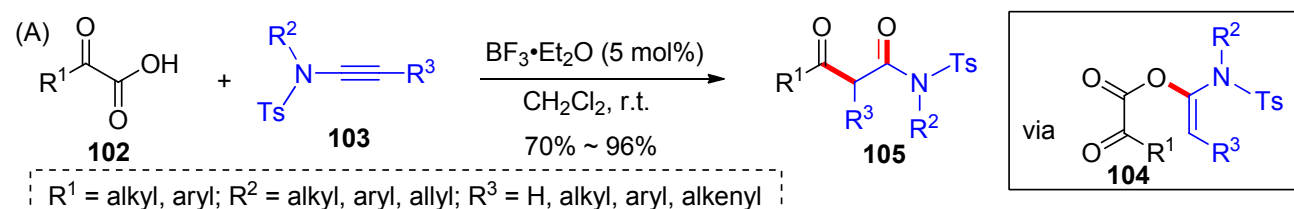

(B)

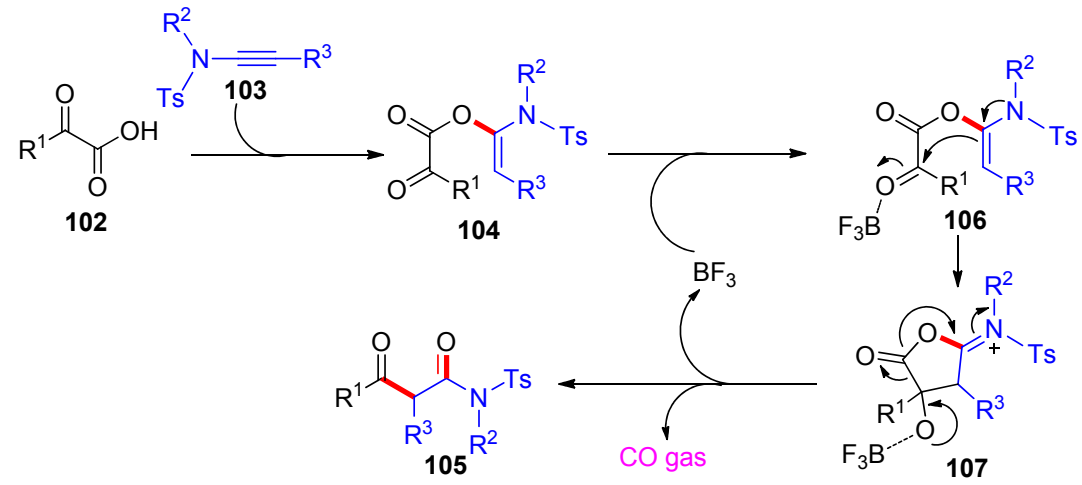

图式 17 炔酰胺和 $\alpha$-酮酸的加成重排反应及反应机理

Scheme 17 Reaction and mechanism of addition/rearrangement between ynamides and $\alpha$-keto acids

(A)
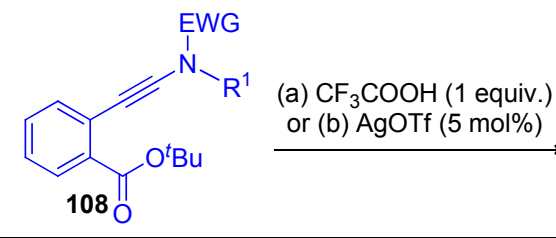
or (b) AgOTf (5 mol\%)<smiles>[R]N(c1cc2ccccc2c(=O)o1)C(C)(C)C</smiles>

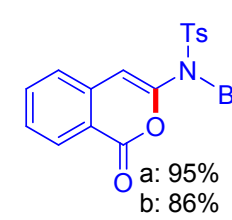<smiles>O=C1CCN1c1cc2ccccc2c(=O)o1</smiles><smiles>C=C1OC(=O)C(N2C(=O)OCC2Br)C1Br</smiles><smiles>O=c1oc(N2Cc3ccccc3S(=O)(=O)C2)cc2ccccc12</smiles><smiles>CCO[18O]CCCN([125I])c1cc2ccccc2c(=O)o1</smiles>

(B)<smiles>O=C(OBr)OC(=O)OC#Cc1ccccc1Cl</smiles>

(1) $\mathrm{R}^{2} \mathrm{R}^{3} \mathrm{NH}$ (1 equiv.), $\mathrm{K}_{3} \mathrm{PO}_{4}$ (2 equiv.) 1,10-phenantroline (20 mol\%) $\mathrm{CuSO}_{4} \cdot 5 \mathrm{H}_{2} \mathrm{O}(10 \mathrm{~mol} \%)$, toluene, $80^{\circ} \mathrm{C}$ (2) $\mathrm{CF}_{3} \mathrm{COOH}$ (1 equiv.), $\mathrm{CH}_{2} \mathrm{Cl}_{2}$, r.t. 110<smiles>CN(Cc1ccccc1)c1cc2cc3ccccc3cc2c(=O)o1</smiles>

$47 \%$<smiles>CN([13CH3])c1cc2nccnc2c(=O)o1</smiles>

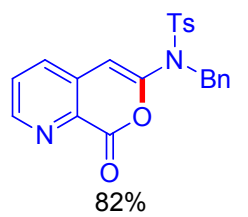<smiles></smiles><smiles>CN([12CH3])c1cc2c(oc3ccccc32)c(=O)o1</smiles>

Ts<smiles>O=C1Cc2ccccc2C=C(N([125I])Cc2ccccc2)O1</smiles>

$68 \%$<smiles>[R]N([R])C1=Cc2ccccc2NC(=O)O1</smiles>
111<smiles>CSc1ncc2cc(N(C)S(C)(F)(F)(F)F)oc(=O)c2n1</smiles><smiles>CN(C)C1=Cc2ccccc2CC(=O)O1</smiles>

图式 18 炔酰胺的分子内氢一酰氧化反应

Scheme 18 Intramolecular hydro-acyloxylation of ynamides

除了羧酸等经典的酸性底物外, $N$-差基邻苯二甲酰 亚胺(NHPI)也具有弱酸性, 其 $\mathrm{p} K_{\mathrm{a}}$ 约为 6.1 , 并呈现了单 电子转移等特殊的化学反应活性 ${ }^{[27]}$. 因此, 我们课题
组 ${ }^{[28]}$ 认为 NHPI 和炔酰胺也可能发生加成反应, 并可能 适用于一系列的自由基反应. 我们开展了大量的尝试与 优化: NHPI (112)和端炔酰胺 113 在二氯甲烷中回流, 可 
以发生加成反应并以化学计量的收率得到产物 114; 除 去二氯甲烷溶剂后，加入芳基硼酸 $115 、 \mathrm{NiCl}_{2} \cdot 6 \mathrm{H}_{2} \mathrm{O}(20$ $\mathrm{mol} \%$ )、二叔丁基联吡定配体(di- $t$ Bubipy, $20 \mathrm{~mol} \%$ )和三 乙胺(10 equiv.), 在二氧六环和 $\mathrm{DMF}$ ( $V: V=10: 1)$ 中 于 $85{ }^{\circ} \mathrm{C}$ 下反应, 发生自由基偶联反应得到 $\alpha$-芳基酰胺 类产物 116 (Scheme 19, A). 当使用 $N$-侧链有烯烃取代 的炔酰胺 117 时, 可以捕获自由基中间体得到环化的内 酰胺产物 118 (Scheme 19, B). 我们也提出了可能的反 应机理(Scheme 20): 首先氯化镍和二叔丁基联吡啶配 体及苯喼酸在三乙胺的作用下形成镍物种 119, NHPI 与 炔酰胺 113 加成生成化合物 114, 114 在镍物种 119 作用 下发生单电子转移(SET)得到自由基物种 120 和镍物种 121; 物种 120 随后发生自由基裂解生成氧自由基物种 123, 并马上重排形成碳自由基 $124 ; 124$ 和镍物种 121 发生自由基加成形成中间体 128, 随后还原消除释放出
产物 116, 并完成镍催化剂循环. 对于炔酰胺 117, 在形 成氧自由基物种 125 后，发生重排得到碳自由基 126 后 继续与分子内烯烃发生自由基环化反应得到碳自由基 127 后，发生自由基加成形成中间体 129 后还原消除生 成产物 118. 在这个工作中, 我们发展的 NHPI、炔酰胺 和芳基硼酸的自由基串联反应，实现了炔酰胺的自由基 多组分反应.

\section{2 炔醚和羧酸的加成反应及应用}

除了炔酰胺，炔醚也是常见的富电子炔烃，并呈现 了差异化的反应活性. 早在 1958 年, Wharton 课题组 ${ }^{[29]}$ 就制备了乙炔甲醚 131, 并利用醋酸采 $(2 \mathrm{~mol} \%$ )作催化 剂, 开发了乙炔甲醚与羧酸 130 的加成反应, 合成了 $\alpha$ 烷氧基烯醇酯( $\alpha$-alkoxy enol esters) 132 (Scheme 21, A).

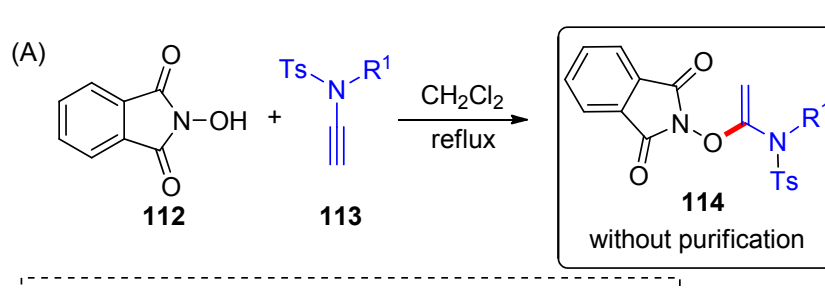

$\mathrm{R}^{1}=$ alkyl; $\mathrm{R}^{2}=\mathrm{H}, \mathrm{Me}, \mathrm{Ph}, \mathrm{OMe}, \mathrm{F}, \mathrm{Cl}, \mathrm{Br}, \mathrm{CN}, \mathrm{COOEt}$

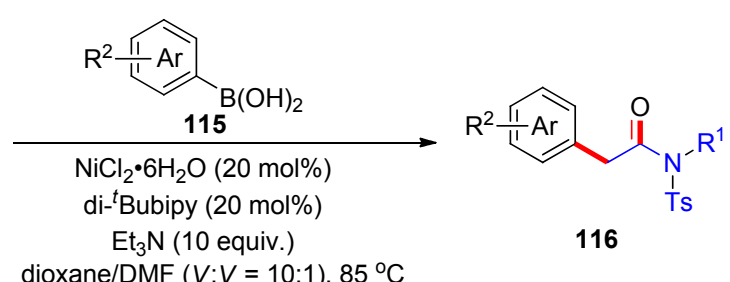
dioxane/DMF $(V: V=10: 1), 85^{\circ} \mathrm{C}$ $44 \% \sim 95 \%$

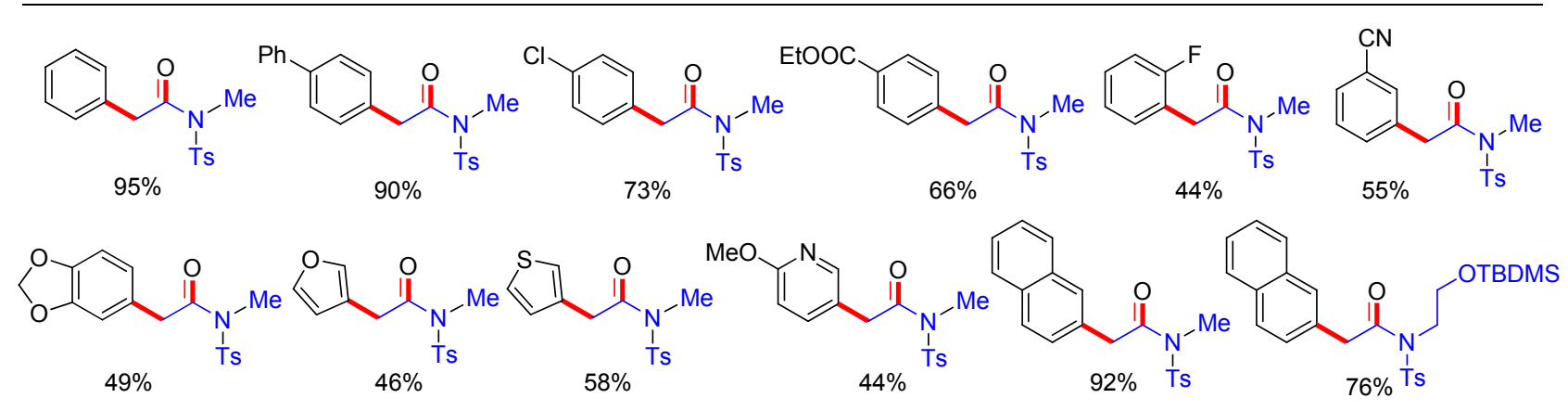

(B)

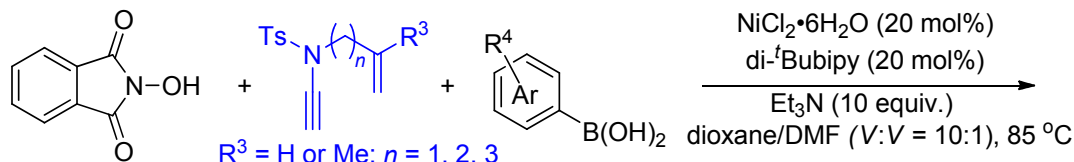
112 117 $36 \% \sim 67 \%$

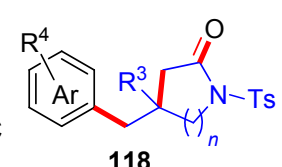<smiles>O=C1CC(Cc2ccc(Cl)cc2)CN1[13S]</smiles>

$50 \%$<smiles>[3H]N1CC(Cc2ccc3ccccc3c2)CC1=O</smiles>

$55 \%$<smiles>Cn1ccc2cc(CC3CC(=O)N([13F])C3)ccc21</smiles>

$65 \%$<smiles>COc1ccc(CC2(C)CC(=O)N([I-])C2)cc1</smiles>

$65 \%$

$46 \%$<smiles>CCOC(=O)c1ccc(CC2CCN([As])C(=O)C2)cc1</smiles>

图式 19 NHPI, 炔酰胺和芳基硼的加成一自由基偶联反应

Scheme 19 Addition and radical coupling of NHPI, ynamides and arylboronic acids 


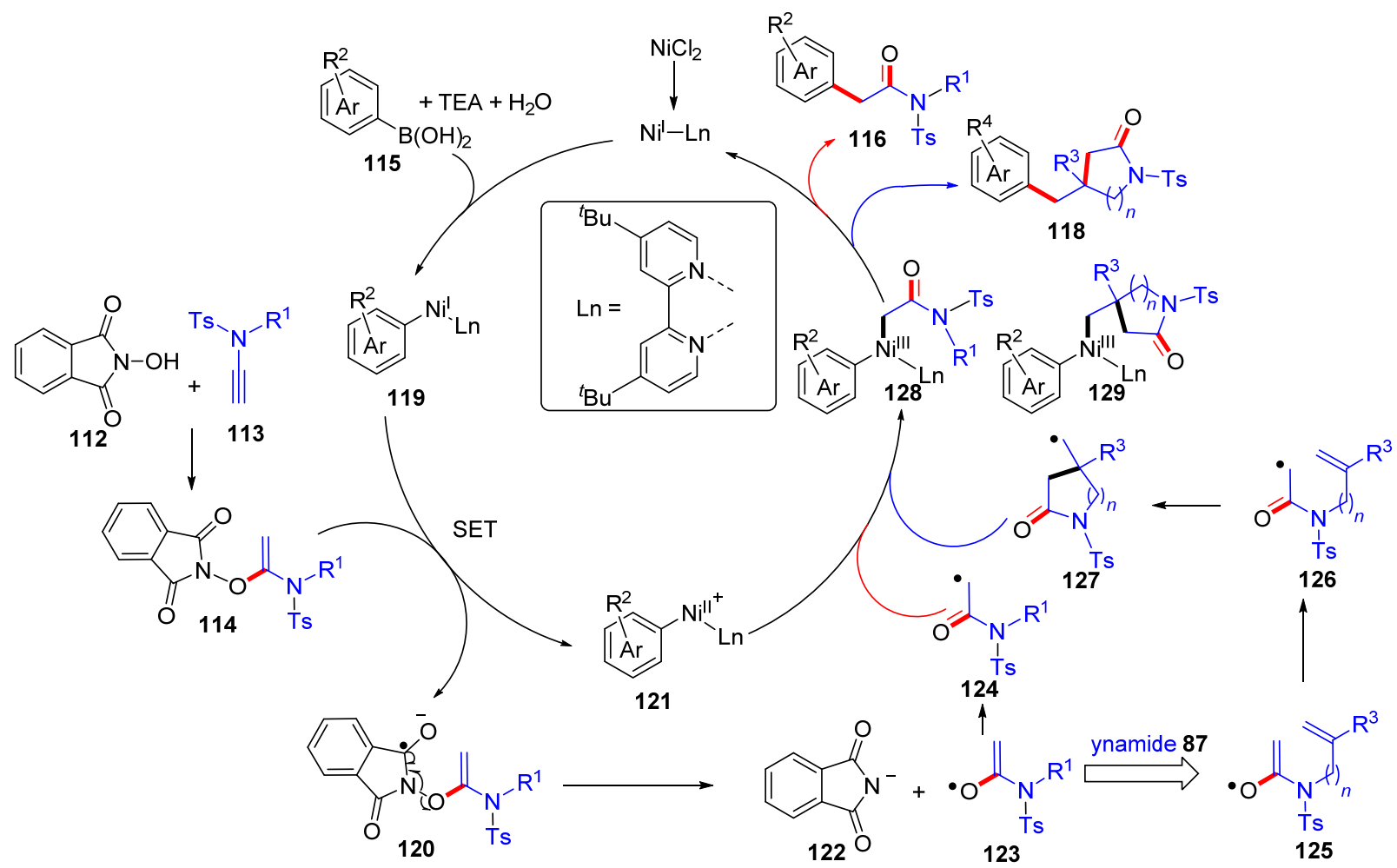

图式 20 NHPI，炔酰胺和芳基硼的加成-自由基偶联反应可能的机理

Scheme 20 Mechanism about addition and radical coupling of NHPI, ynamides and arylboronic acids

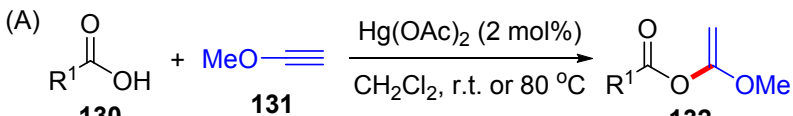

$$
\begin{aligned}
& 130131
\end{aligned}
$$<smiles>C=C(OC)OC(C)=O</smiles><smiles>C=C(OC)OC(=O)c1ccccc1</smiles>
$98 \%$<smiles>C=C(OC)OC(=O)c1cc([N+](=O)[O-])cc([N+](=O)[O-])c1</smiles><smiles>C=C(OC)OC(=O)c1ccc(/N=N/c2ccccc2)cc1</smiles>

(B)

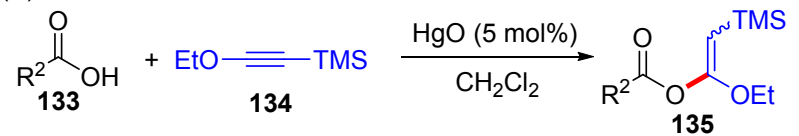

图式 $21 \mathrm{Hg}$ 催化炔醚和羧酸的加成反应

Scheme $21 \mathrm{Hg}$-Catalyzed addition reaction between ynol ethers and carboxylic acids

为了克服端炔醚稳定性差的问题, Kita 研究组 ${ }^{[30]}$ 制备了 TMS 取代的炔醚 134; 发现在氧化录 (5 mol\%)的催化下, 羧酸 133 和炔醚 134 可发生加成反应, 生成 $\alpha$-烷氧基烯 醇酯 135 (Scheme 21, B). 同时, 炔醚 131 或 134 可以作 为有机合成缩合剂(Scheme 22). 例如, 在 $\mathrm{Hg}$ 试剂的作 用下，炔醚可以作为缩合试剂, 将羧酸 136 和二羧酸
137 分别转化成酸䣶 138 和 $139^{[31]}$. 而且, 羧酸 140 和炔 醚发生加成反应得到 $\alpha$-烷氧基烯醇酯产物后, 加入胺 141 和羟基化合物 142 可以分别制备酰胺 143 和酯 $144^{[32]}$. 然而, 上述工作都需要用到剧毒的 $\mathrm{Hg}$ 试剂, 这 限制了炔醚和羧酸加成反应的应用. 因此, 发展温和条 件下的炔醚的氢一酰氧化反应非常迫切。

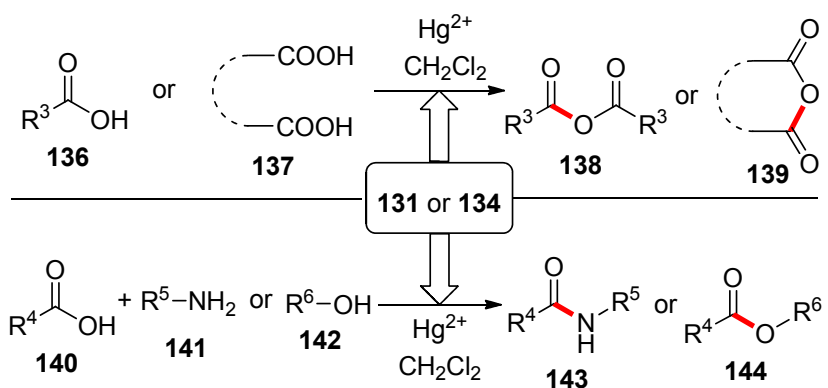

图式 22 炔醚用于酸酐、酰胺和酯的合成

Scheme 22 Synthesis of anhydrides, amides and esters using ynol ethers

2014 年, 朱钢国研究组 ${ }^{[33]}$ 报道了银催化的炔醚和 羧酸的加成反应实现氢-酰氧化. 他们通过条件篮选发 现：在氧化银(5 mol\%)作用下，将羧酸 145 和炔醚 146 在 1,4-二氧六环(dioxane)中于 $100{ }^{\circ} \mathrm{C}$ 下加热反应可以高 效制备 $Z$ 式 $\alpha$-烷氧基烯醚 147 (Scheme 23, A); 该反应具 有优秀的区域选择性和立体选择性. 底物范围广, 


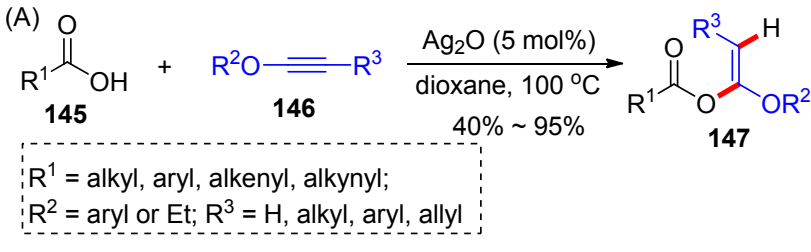

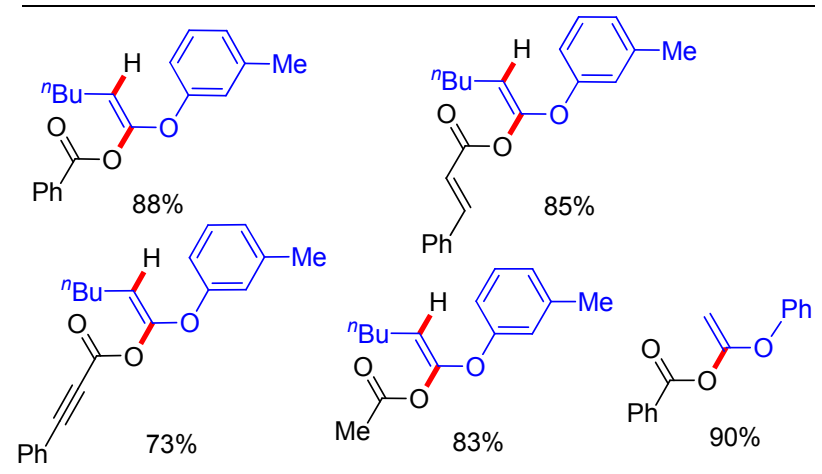

(B)

图式 $23 \mathrm{Ag}$ 催化炔醚和羧酸的加成反应

Scheme 23 Ag-Catalyzed addition reaction between ynol ethers and carboxylic acids

各类脂肪酸、芳香酸、不饱和烯酸和炔酸, 以及各类端 炔醚、烷基、芳基或烯丙基取代的炔醚, 都可以适用该 加成反应. 对该加成反应的应用也进行了研究, 例如, 使用特戊酸和炔醚得到的氢-酰氧化产物 148 , 可以在 $\mathrm{Ni}\left(\mathrm{PCy}_{3}\right)_{2} \mathrm{Cl}_{2}$ (4 mol\%)的催化下与芳基硼酸 149 发生 Suzuki-Miyaura 偶联反应, 制备三取代的烯醚类化
合物 150 (Scheme 23, B). 该工作为炔醚和羒酸之间的 加成反应提供了非常温和条件, 为之后该反应的应用提 供了基础.

2018 年, 结合前期在炔酰胺参与的多组分反应的 工作基础, 我们课题组 ${ }^{[34]}$ 发展了炔醚、羧酸和二氢异喹 啉(DHIQs)的三组分反应, 高效合成了四氢异喹啉 (THIQs)类化合物(Scheme 24). 在氧化银 (5 mol\%)催化 下, 羧酸 151 和炔醚 152 于二氧六环中加热原位生成 $\alpha$ 烷氧基烯醇酯，该中间体可以与二氢异喹啉 153 在 $100{ }^{\circ} \mathrm{C}$ 下反应，高效制备了四氢异喹啉类产物 $\mathbf{1 5 4}$. 羧 酸、炔醚以及二氢异喹啉的底物普适性都良好. 不足的 是，当使用内炔醚时，反应的产率相比端炔醚大大降低. 随后，我们应用该方法做了一些合成应用(Scheme 25, A)：例如，四氢异喹啉产物 $\mathbf{1 5 5}$ 经过脱去芐氧羰基 $(\mathrm{Cbz})$ 保护后, 可以直接发生分子内环化形成七元杂环化合物 156; 产物 157 经过还原硝基成氨基后可以环化成八元 杂环化合物 158; 而咔唑类产物 159 在 1,8 二氮杂二环 十一碳-7-烯(DBU)的作用下发生分子内缩合反应串联 $\beta$-消除反应, 得到吲哚并五元环类产物 161 . 为了探究 机理, 我们开展了一系列的控制实验, 发现 $\alpha$-烷氧基烯 醇酯中间体和二氢异喹啉不需要任何催化剂作用就可 以反应. 于是, 我们提出了可能的反应历程(Scheme 25, B): 在氧化银催化下, 羧酸 151 和炔醚 152 原位生成 $\alpha$ 烷氧基烯醚 162; 然后，二氢异喹啉 153 对 162 的羰基发 生加成反应形成中间体 163 ; 最后, 163 发生分子内重排 反应即可得到产物 154 . 该反应是基于炔梄的第一个多
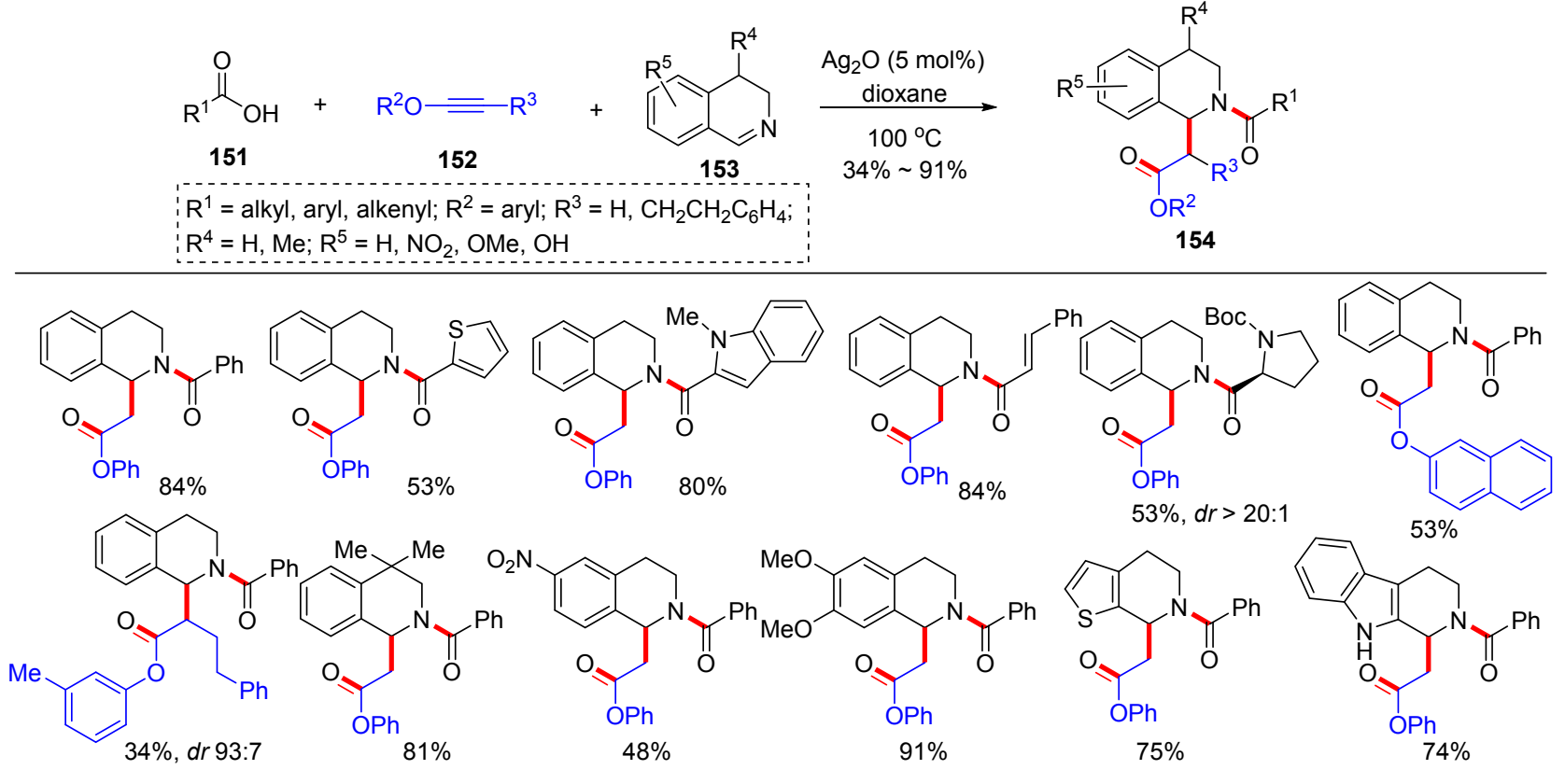

图式 24 三组分合成四氢异喹啉

Scheme 24 Three-component synthesis of tetrahydroisoquinolines 


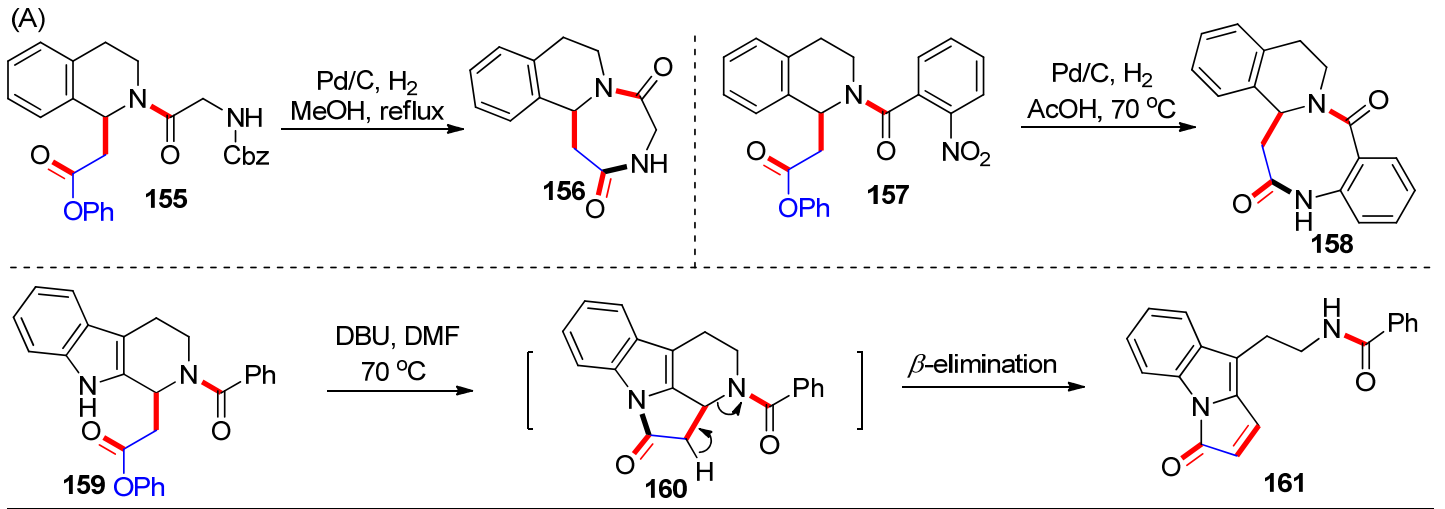

(B)<smiles>[R20]C#CO[R2]</smiles>

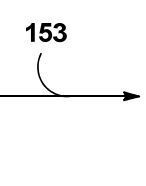

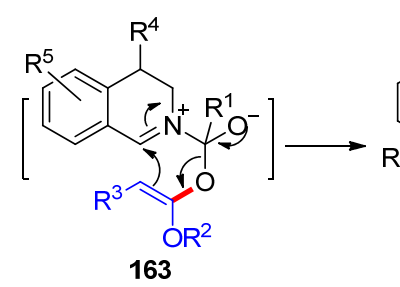

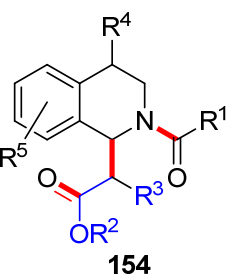

图式 25 三组分合成四氢异喹啉的应用及可能机理

Scheme 25 Applications and mechanism about three-component synthesis of tetrahydroisoquinolines

组分反应, 也为优势骨架四氢异喹啉类化合物的合成提 供了实用的方法.

之后, 我们课题组 ${ }^{[35]}$ 又继续探究了炔醚和羧酸加 成反应在有机合成中的应用, 发现在氧化银催化下, 羧 酸 164 和炔醚 165 形成 $\alpha$-烷氧基烯醚 166 后, 在催化量 的 4-二甲氨基吡啶(DMAP, 167, $20 \mathrm{~mol} \%$ )作用下，可以 发生重排得到 $\beta$-羰基酯类化合物 $168 ; 166$ 也可以与间氯 过氧苯甲酸 $(m-C P B A, 169)$ 发生氧化重排反应, 得到 $\alpha$ 酰氧基酯类产物 $\mathbf{1 7 0}$ (Scheme 26, A). 以上两类反应的 底物普适性良好, 适用于各类羧酸和炔醚. 可能的反应 历程(Scheme 26, B)为: 在氧化银作用下, 羧酸 164 和炔 醚 165 原位生成 $\alpha$-烷氧基烯醚 166, 加入 DMAP 后, 可 以对羰基进行加成得到中间体 171, 随后 171 发生分子 内的重排反应, 释放出产物 168, DMAP 则完成了循环; 而当 $\alpha$-烷氧基烯醚 166 碰到 $m$-CPBA, 可能经过缩合过 程生成中间体 172, 随后发生分子内重排生成 $\alpha$-酰氧基 酯类产物 170 和过氧苯甲酸, 这一过程与经典的 BaeyerVilliger 反应有点类似. 上述反应, 是我们课题组从炔醚 和羧酸的氢一酰氧化反应出发, 通过合理设计优化成功 实现的三组分或者一锅法重排反应的方法学, 丰富了炔 醚化学和杂环化合物的合成研究.

\section{3 其他富电子炔烃和羧酸的反应}

除了炔酰胺和炔醚, 其他的富电子炔烃也可以与羧 酸发生加成反应. 炔胺是较早报道的富电子炔烃之一, 但由于性质极其不稳定, 大大限制了它们在有机化学中 的应用, 因而关于炔胺的反应研究仅有少数的例子.
1996 年, Neuenschwander 等 ${ }^{[36]}$ 制备了几个不同结构的炔 胺 174, 并分别尝试了其与醋酸 173 的反应，发现两者 在乙醚中于 $3{ }^{\circ} \mathrm{C}$ 下反应, 就可以快速生成 $\alpha$-酰氧基烯 胺产物 175 (Scheme 27). 2018 年, Kunishima 课题组 ${ }^{[37]}$ 在研究环丙烯酮和羧酸的反应机理时, 做了以下实验: 将环丙烯酮 176 在录灯作用下原位生成炔胺 178 后，与 苯丙酸 177 反应, 以 $74 \%$ 的收率得到了 $\alpha$-酰氧基烯胺 179 (Scheme 28). 以上反应无需任何催化剂, 反应在较 低温度下进行, 说明炔胺的活性比炔酰胺和炔醚都要 高，这也反映了炔胺类化合物的不稳定性.

$N$-炔基砜亚胺( $N$-alkynyl sulfoximines) 是由 Bolm 研 究组 ${ }^{[38]}$ 设计合成的一类富电子炔烃. 他们研究组 ${ }^{[39]}$ 发 现在四氢呋喃(THF)中, 羧酸 180 在室温下可以与该类 炔烃 181 反应, 得到以 $E$ 式为主的氢一酰氧化产物 182 (Scheme 29). 该反应不需要任何的催化剂并具有较高 的反应收率. 各类脂肪羧酸和芳香羧酸都适用于该加成 反应，并具有良好的区域选择性和立体选择性.

2015 年, Severin 课题组 ${ }^{[1 \mathrm{k}]}$ 报道了一类 1-炔基三氮 烯(1-alkynyltriazenes)的制备，在氨基锂试剂与笑气 $\left(\mathrm{N}_{2} \mathrm{O}\right)$ 发生加成之后，继续与炔基格式试剂反应可以制 备该类炔烃. 1-炔基三氮烯也呈现了富电子炔烃的特 点 $^{[40]} .2015$ 年, Severin 课题组 ${ }^{[41]}$ 发现 1-炔基三氮烯和炔 酰胺有着类似的反应活性: 羧酸 183 和 1-炔基三氮烯 184 在高温下可以发生加成反应, 生成氢一酰氧化产物 185, 反应收率高, 区域选择性和立体选择性也较好 (Scheme 30, A). 此外, 丙酮和水的混合溶剂中，1-炔基 三氮烯 186 和醋酸 187 可以发生加成反应, 并水解为酰 
(A)

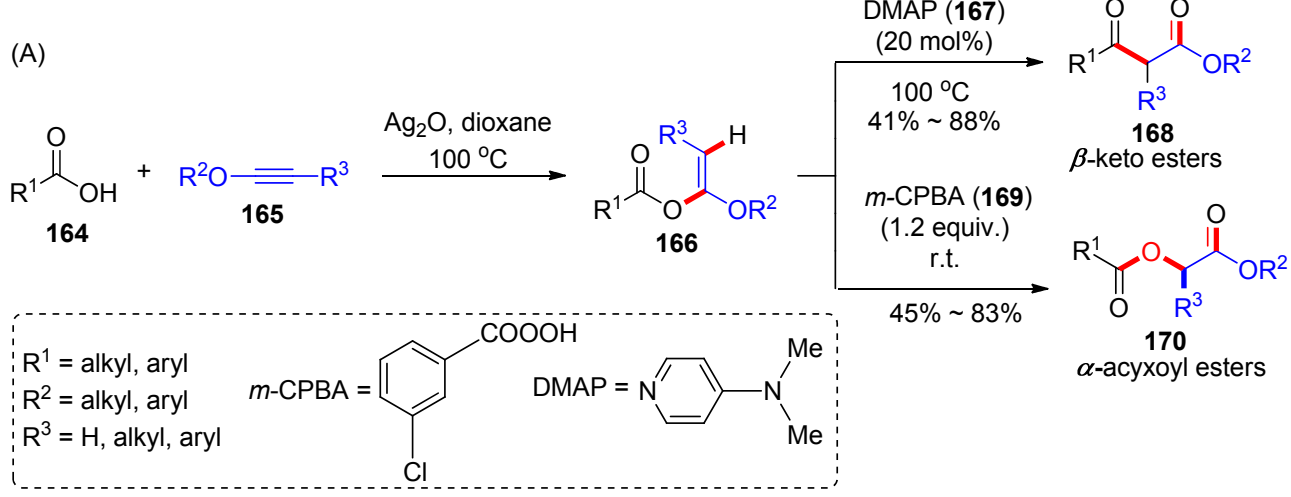

(B)

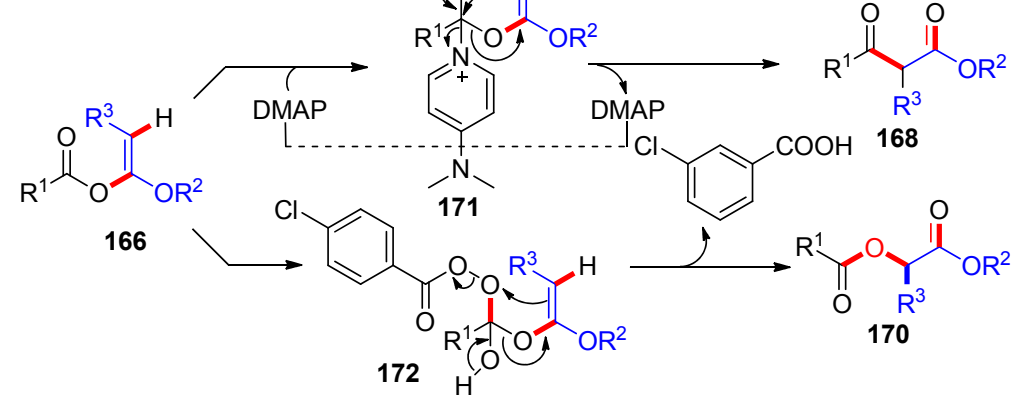

图式 26 一锅法制备 $\beta$-羰基酯和 $\alpha$-酰氧基酯的反应及机理

Scheme 26 Reactions and mechanism of one-pot synthesis of $\beta$-keto-esters and $\alpha$-acyxoyl esters

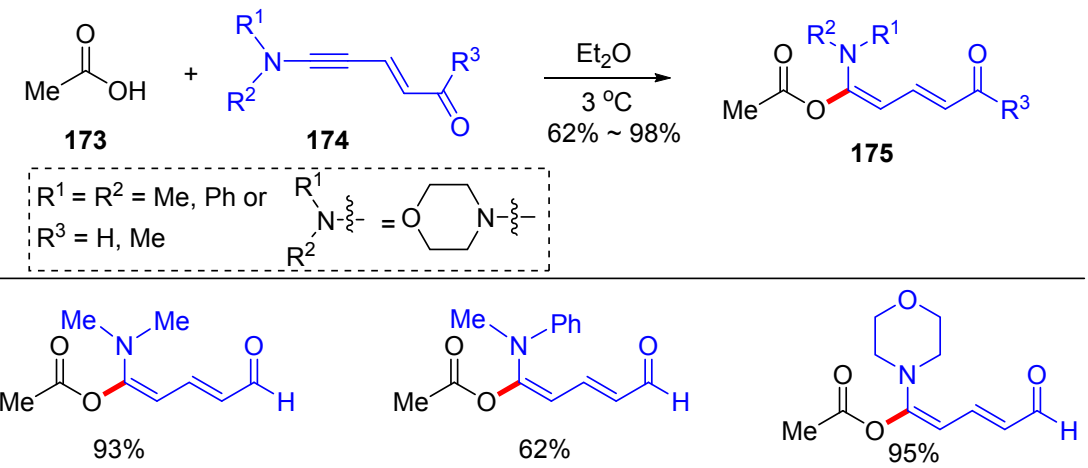<smiles>CC(=O)/C=C/C=C(/OC(C)=O)N(C)C</smiles><smiles>CC(=O)/C=C/C=C(/OC(C)=O)N(C)c1ccccc1</smiles><smiles>CC(=O)/C=C/C=C(/OC(C)=O)N1CCOCC1</smiles>

图式 27 醋酸和炔胺的加成反应

Scheme 27 Addition reaction between acetic acid and ynamines

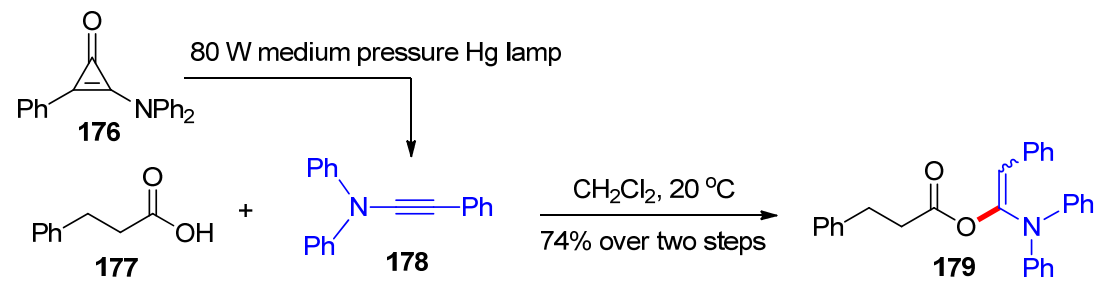

图式 28 羧酸和原位生成炔胺的加成反应

Scheme 28 Addition reaction between carboxylic acids and in situ generated ynamines 

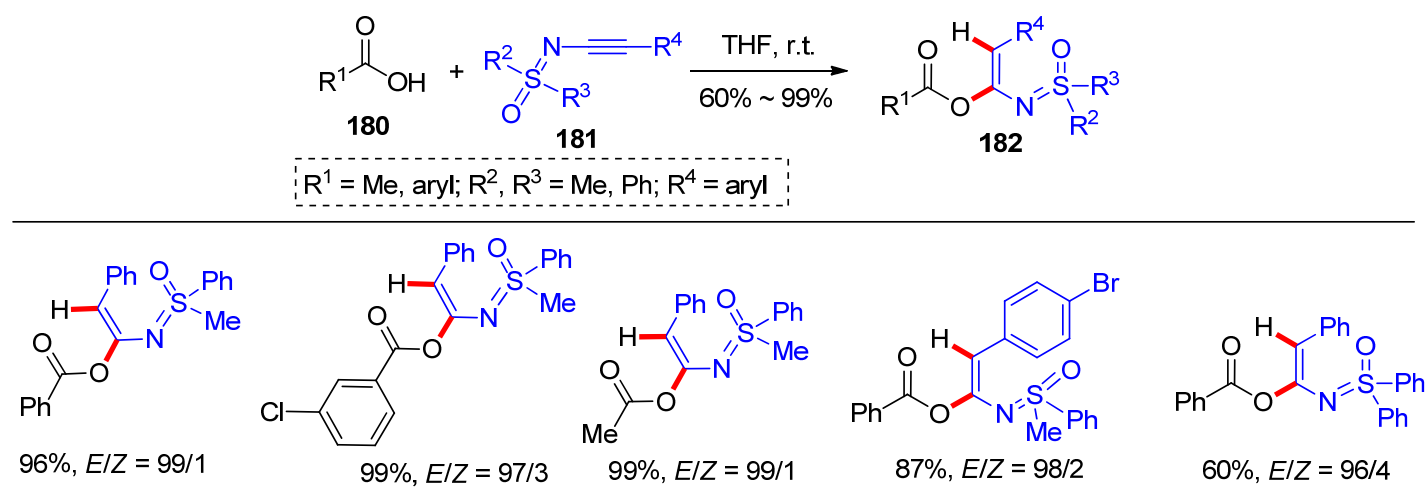

图式 29 羧酸和 $N$-炔基砜亚胺的加成反应

Scheme 29 Addition reaction between acetic acids and $N$-alkynyl sulfoximines

(A)

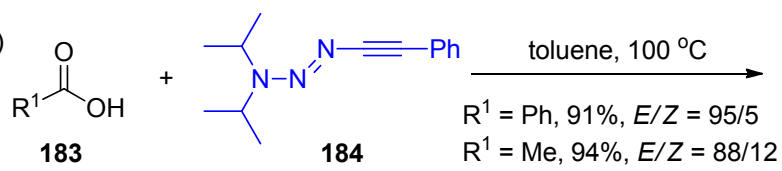<smiles>[R]C(=O)OC(=Cc1ccccc1)NN(C(C)C)C(C)C</smiles>

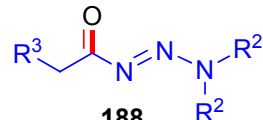

(B)

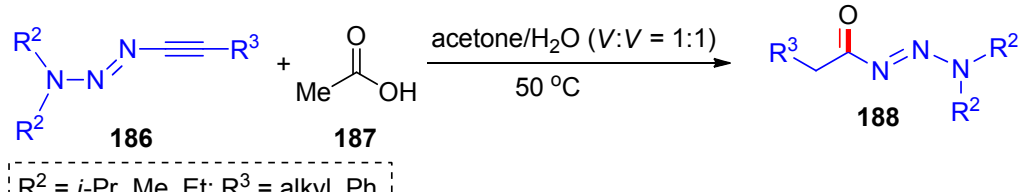

$\mathrm{R}^{2}=\mathrm{i}-\mathrm{Pr}, \mathrm{Me}, \mathrm{Et} ; \mathrm{R}^{3}=\mathrm{alkyl}, \mathrm{Ph}$<smiles>CC(C)N(N=NC(=O)CCc1ccccc1)C(C)C</smiles><smiles>CC(C)N(NNC(=O)CBr)C(C)C</smiles><smiles>CC(C)N(NNC(=O)Cc1ccccc1)C(C)C</smiles><smiles>COCCC(=O)NN(C(C)C)C(C)C</smiles><smiles>CC(C)N(N=NC(=O)CC1CCCC1)C(C)C</smiles>

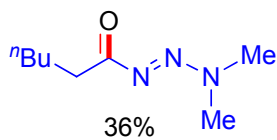

图式 30 羧酸和 1-炔基三嗪的加成反应

Scheme 30 Addition reaction between carboxylic acid and 1-alkynyltriazenes

基三氮烯 188 (Scheme 30, B), 这类酰基三嗪化合物类 被认为是一种酰基化试剂, 可以用于各类反应 ${ }^{[42]}$.

2-炔基苯酚类化合物也可以被认为是一类富电子 炔烃，因为羟基的供电子效应可以通过苯环共轭传递到 炔烃上. 我们课题组 ${ }^{[33]}$ 在研究 2-炔基苯酚的过程中, 发 现在 $\left[\operatorname{Ir}(\operatorname{cod}) \mathrm{Cl}_{2}\right]_{2}(1 \mathrm{~mol} \%)$ 的催化下, 羧酸 189 和 2-炔基 苯酚 190 反应, 可以高效实现氢-酰氧化制备单一 $E$ 型 的羧酸烯醇酯 191, 并具有良好的区域选择性、立体选 择性和产率, 产物只需重结晶或者简单的浓缩即可得到 纯品 191. 有趣的是, 如果对该反应进行硅胶柱层析, 只能得到 2-酰氧基苯乙酮类化合物 192, 192 是通过 191 的分子内酰基迁移反应产生的(Scheme 31, A). 因此, 该 加成反应后可以通过改变纯化方式, 选择性地制备两种 不同的产物. 另外, 得到的 2-酰氧基苯乙酮类化合物也 可以继续作为 Baker-Venkataraman 重排反应的原料, 进 行各类反应转化. 比如, 将化合物 193 在氢化钠 $(\mathrm{NaH})$
作用下发生重排，直接在盐酸和醋酸中回流，可以制备 黄酮类母核化合物 194 (Scheme 31, B).

\section{4 总结与展望}

综上所述, 富电子炔烃和羧酸的氢一酰氧化反应取 得了较大的研究进展; 尤其炔酰胺、炔醚和羧酸的加成 反应，已经在多肽合成、多组分反应、一锅法反应、重 排反应以及自由基反应等领域被广泛使用. 对于富电子 炔烃和羧酸的加成反应及其合成应用的发展前景，我们 认为以下几点值得关注: (1)继续探索炔硫醚、2-炔基苯 胺等富电子炔烃和羧酸的氢-酰氧化反应; (2)设计新型 的富电子炔烃，探索它们和羧酸的氢一酰氧化反应及应 用; (3)将已经开发的富电子炔烃和羧酸的加成反应, 应 用于更多的有机合成中. 我们相信, 以富电子炔烃和羧 酸的加成反应为基础, 开展的新型有机反应研究是一个 绿色合成的重要研究方向, 在未来会迎来更大的发展. 


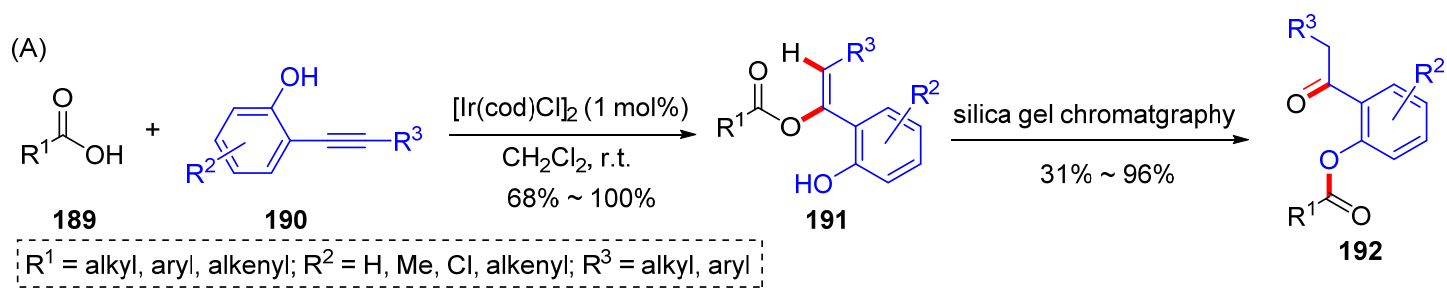

\section{1}<smiles>O=C(OC(=Cc1ccccc1)c1ccccc1O)c1ccccc1</smiles>

$91 \%$<smiles>O=C(OC(=Cc1ccccc1)c1ccccc1O)c1cccs1</smiles><smiles>O=C(O/C(=C/c1ccccc1)c1ccccc1O)C1CCOCC1</smiles>

$85 \%$<smiles>O=C(O/C(=C/c1ccccc1Cl)c1ccccc1O)c1ccccc1</smiles><smiles>O=C(O/C(=C/c1ccc(F)cc1)c1ccccc1O)c1ccccc1</smiles>

$92 \%$<smiles>O=C(OC(=Cc1ccccc1)c1ccccc1O)c1ccc2ccccc2c1</smiles>

$89 \%$ $90 \%$

(B)<smiles>[R3]CC(=O)c1c([R])cccc1OC([R])=O</smiles><smiles>CC(=O)Oc1ccccc1C(=O)Cc1ccccc1</smiles><smiles>O=C(Oc1ccccc1C(=O)Cc1ccccc1)c1ccccc1</smiles>

$89 \%$<smiles>O=C(Cc1ccccc1)Oc1ccccc1C(=O)Cc1cccs1</smiles>

$68 \%$<smiles>O=C(Cc1ccccc1)c1ccccc1OC(=O)C1CC1</smiles><smiles>CC(C)(C)OC(=O)c1ccccc1C(=O)Oc1ccccc1C(=O)Cc1ccccc1</smiles>

$86 \%$<smiles>CC(C)(C)n1ccc2ccccc21</smiles><smiles>O=C(/C=C/c1ccccc1)Oc1ccccc1C(=O)Cc1ccccc1</smiles><smiles>O=C(Cc1ccccc1)Oc1ccccc1C(=O)CC1CC1</smiles><smiles></smiles>

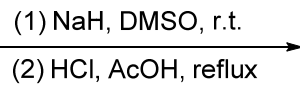<smiles>[R]c1oc2cccc([R])c2c(=O)c1[R]</smiles>

193

194<smiles>O=c1c(-c2ccccc2)c(-c2ccc3ccccc3c2)oc2ccccc12</smiles>

$69 \%$<smiles>O=c1c(-c2ccccc2)c(-c2ccco2)oc2ccccc12</smiles>

$86 \%$<smiles>O=c1c(-c2ccccc2)c(-c2cccs2)oc2ccccc12</smiles>

$91 \%$<smiles>O=c1c(-c2ccccc2)c(C2CCOCC2)oc2ccccc12</smiles>

$90 \%$

图式 31 羧酸和邻炔基苯酚的加成反应

Scheme 31 Addition reaction of carboxylic acids and 2-alkynylphenols

\section{References}

[1] (a) Janousek, Z.; Viehe, H. G.; Collard, J. Angew. Chem., Int. Ed. 1972, 11, 917.

(b) Tu, Y.; Zeng, X.; Wang, H.; Zhao, J. Org. Lett. 2018, 20, 280.

(c) Coste, A.; Karthikeyan, G.; Couty, F.; Evano, G. Angew. Chem., Int. Ed. 2009, 48, 4381.

(d) Frederick, M. O.; Mulder, J. A.; Tracey, M. R.; Hsung, R. P.; Huang, J.; Kurtz, K. C. M.; Shen, L. C.; Douglas, C. J. J. Am. Chem. Soc. 2003, 125, 2368.

(e) Mansfield, S. J.; Campbell, C. D.; Jones, M. W.; Anderson, E. A. Chem. Commun. 2015, 51, 3316

(f) Souto, J. A.; Becker, P.; Iglesias, A.; Muniz, K. J. Am. Chem. Soc. 2012, 134, 15505.

(g) Zhang, X. J.; Zhang, Y. S.; Huang, J.; Hsung, R. P.; Kurtz, K. C.
M.; Oppenheimer, J.; Petersen, M. E.; Sagamanova, I. K.; Shen, L. C.; Tracey, M. R. J. Org. Chem. 2006, 71, 4170.

(h) Jouvin, K.; Coste, A.; Bayle, A.; Legrand, F.; Karthikeyan, G.; Tadiparthi, K.; Evano, G. Organometallics 2012, 31, 7933.

(i) Jouvin, K.; Bayle, A.; Legrand, F.; Evano, G. Org. Lett. 2012, 14, 1652.

(j) Kanemoto, K.; Yoshida, S.; Hosoya, T. Org. Lett. 2019, 21, 3172 .

(k) Kiefer, G.; Riedel, T.; Dyson, P. J.; Scopelliti, R.; Severin, K. Angew. Chem., Int. Ed. 2015, 54, 302.

(1) Pena, J.; Talavera, G.; Waldecker, B.; Alcarazo, M. Chem.-Eur. J. 2017, 23, 75 .

[2] (a) Wang, X. N.; Yeom, H. S.; Fang, L. C.; He, S. H.; Ma, Z. X.; Kedrowski, B. L.; Hsung, R. P. Acc. Chem. Res. 2014, 47, 560.

(b) Pan, F.; Shu, C.; Ye, L. W. Org. Biomol. Chem. 2016, 14, 9456. 
(c) Wang, Y.; Song, L. J.; Zhang, X. H.; Sun, J. W. Angew. Chem., Int. Ed. 2016, 55, 9704 .

(d) Zhu, C.; Feng, J.; Zhang, J. Chin. J. Org. Chem. 2017, 37, 1165 (in Chinese).

(朱超泽，冯见君，张俊良，有机化学, 2017, 37, 1165.)

(e) Liu, J.; Chakraborty, P.; Zhang, H.; Zhong, L.; Wang, Z.; Huang, X. ACS Catal. 2019, 9, 2610.

[3] (a) Marion, F.; Courillon, C.; Malacria, M. Org. Lett. 2003, 5, 5095.

(b) Banerjee, B.; Litvinov, D. N.; Kang, J.; Bettale, J. D.; Castle, S.

L. Org. Lett. 2010, 12, 2650.

(c) Wang, L.; Lu, C. R.; Yue, Y. N.; Feng, C. Org. Lett. 2019, 21, 3514 .

[4] (a) Shen, C.-H.; Li, L.; Zhang, W.; Liu, S.; Shu, C.; Xie, Y.-E.; Yu, Y.-F.; Ye, L.-W. J. Org. Chem. 2014, 79, 9313.

(b) Liu, R. H.; Winston-McPherson, G. N.; Yang, Z. Y.; Zhou, X.; Song, W. Z.; Guzei, I. A.; Xu, X. F.; Tang, W. P. J. Am. Chem. Soc. 2013, 135, 8201 .

(c) Davies, P. W.; Cremonesi, A.; Martin, N. Chem. Commun. 2011, 47, 379 .

[5] (a) Ding, S. T.; Jia, G. C.; Sun, J. W. Angew. Chem., Int. Ed. 2014, $53,1877$.

(b) Tian, X. H.; Song, L. N.; Rudolph, M.; Rominger, F.; Oeser, T.; Hashmi, A. S. K. Angew. Chem., Int. Ed. 2019, 58, 3589.

(c) DeKorver, K. A.; Li, H. Y.; Lohse, A. G.; Hayashi, R.; Lu, Z. J.; Zhang, Y.; Hsung, R. P. Chem. Rev. 2010, 110, 5064.

(d) Zhou, B.; Li, L.; Zhu, X. Q.; Yan, J. Z.; Guo, Y. L.; Ye, L. W. Angew. Chem., Int. Ed. 2017, 56, 4015.

(e) Zeng, L.; Lai, Z.; Zhang, C.; Xie, H.; Cui, S. Org. Lett. 2020, 22, 2220 .

[6] (a) Zhang, W. H.; Ready, J. M. J. Am. Chem. Soc. 2016, 138, 10684.

(b) Zhang, Y.; Hsung, R. P.; Zhang, X.; Huang, J.; Slafer, B. W.; Davis, A. Org. Lett. 2005, 7, 1047.

(c) Couty, S.; Liegault, B.; Meyer, C.; Cossy, J. Tetrahedron 2006, 62, 3882 .

(d) Couty, S.; Meyer, C.; Cossy, J. Tetrahedron Lett. 2006, 47, 767. (e) Alayrac, C.; Schollmeyer, D.; Witulski, B. Chem. Commun. 2009, 1464.

[7] (a) Cao, W.; Chen, P.; Wang, L.; Wen, H.; Liu, Y.; Wang, W. S.; Tang, Y. Org. Lett. 2018, 20, 4507.

(b) Compain, G.; Jouvin, K.; Mingot, A. M.; Evano, G.; Marrot, J.; Thibaudeau, S. Chem. Commun. 2012, 48, 5196.

(c) Métayer, B.; Compain, G.; Jouvin, K.; MartinMingot, A.; Bachmann, C.; Marrot, J.; Evano, G.; Thibaudeau, S. J. J. Org. Chem. 2015, 80, 3397.

(d) Zeng, X. J.; Lu, Z. C.; Liu, S. W.; Hammond, G. B.; Xu, B. J. Org. Chem. 2017, 82, 13179.

(e) Li, X.; Sun, Y.; Zhang, L.; Peng, B. Chin. J. Org. Chem. 2016, 36, 2530 (in Chinese).

(李晓锦, 孙艳, 张磊, 彭勃, 有机化学, 2016, 36, 2530.)

[8] (a) Kanemura, S.; Kondoh, A.; Yasui, H.; Yorimitsu, H.; Oshima, K. Bull. Chem. Soc. Jpn. 2008, 81, 506.

(b) Yasui, H.; Yorimitsu, H.; Oshima, K. Chem. Lett. 2008, 37, 40.

(c) Kim, S. W.; Um, T. W.; Shin, S. Chem. Commun. 2017, 53, 2733.

[9] (a) Tolchinskii, S. E.; Dogadina, A. V.; Maretina, I. A.; Petrov, A. A. Zh. Org. Khim. 1980, 16, 1141.

(b) Yoo, H. J.; Youn, S. W. Org. Lett. 2019, 21, 3422.

[10] (a) Rentsch, C.; Slongo, M.; Stadelma, W.; Neuensch, M. Chimia 1973, 27, 70 .

(b) Zhang, Y.; DeKorver, K. A.; Lohse, A. G.; Zhang, Y. S.; Huang, J.; Hsung, R. P. Org. Lett. 2009, 11, 899.

(c) DeKorver, K. A.; Johnson, W. L.; Zhang, Y.; Hsung, R. P.; Dai, H. F.; Deng, J.; Lohse, A. G.; Zhang, Y. S. J. Org. Chem. 2011, 76, 5092 .

[11] (a) Bianchini, C.; Meli, A.; Peruzzini, M.; Zanobini, F.; Bruneau, C.; Dixneuf, P. H. Organometallics 1990, 9, 1155.

(b) Chen, J.-F.; Li, C. Org. Lett. 2018, 20, 6719. (c) Goossen, L. J.; Paetzold, J.; Koley, D. Chem. Commun. 2003, 706

(d) Hua, R. M.; Tian, X. J. Org. Chem. 2004, 69, 5782.

(e) Jeschke, J.; Gabler, C.; Lang, H. J. Org. Chem. 2016, 81, 476.

(f) Lumbroso, A.; Vautravers, N. R.; Breit, B. Org. Lett. 2010, 12, 5498.

(g) Rotem, M.; Shvo, Y. Organometallics 1983, 2, 1689.

(h) Wang, Y.; Wang, Z.; Li, Y.; Wu, G.; Cao, Z.; Zhang, L. Nat Commun. 2014, 5, 3470.

(i) Dupuy, S.; Gasperini, D.; Nolan, S. P. ACS Catal. 2015, 5, 6918.

[12] Smith, D. L.; Goundry, W. R. F.; Lam, H. W. Chem. Commun 2012, 48, 1505.

[13] Xu, S.; Liu, J.; Hu, D.; Bi, X. Green Chem. 2015, 17, 184

[14] (a) Hu, L.; Xu, S.; Zhao, Z.; Yang, Y.; Peng, Z.; Yang, M.; Wang, C.; Zhao, J. J. Am. Chem. Soc. 2016, 138, 13135 (b) Hu, L.; Zhao, J. Synlett 2017, 28, 1663.

[15] Yang, J.; Wang, C.; Xu, S.; Zhao, J. Angew. Chem., Int. Ed. 2019, $58,1382$.

[16] Wang, X.; Yang, Y.; Zhao, Y.; Wang, S.; Hu, W.; Li, J.; Wang, Z.; Yang, F.; Zhao, J. J. Org. Chem. 2020, 85, 6188.

[17] Yang, M.; Wang, X.; Zhao, J. ACS Catal. 2020, 10, 5230.

[18] Huang, B.; Zeng, L.; Shen, Y.; Cui, S. Angew. Chem., Int. Ed. 2017, $56,4565$.

[19] Shen, Y.; Huang, B.; Zeng, L.; Cui, S. Org. Lett. 2017, 19, 4616.

[20] (a) Quinone Methides, Ed.: Rokita, S. E., Wiley, New York, 2009. (b) Yang, B.; Gao, S. Chem. Soc. Rev. 2018, 47, 7926.

[21] Chen, R.; Liu, Y.; Cui, S. Chem. Commun. 2018, 54, 11753.

[22] Shen, Y.; Li, Q.; Xu, G.; Cui, S. Org. Lett. 2018, $20,5194$.

[23] Shen, Y.; Wang, C.; Chen, W.; Cui, S. Org. Chem. Front. 2018, 5 , 3574.

[24] (a) Pusterla, I.; Bode, J. W. Angew. Chem., Int. Ed. 2012, 51, 513. (b) Doll, M. K. H. J. Org. Chem. 1999, 64, 1372.

(c) Gooßen, L. J.; Rudolphi, F.; Oppel, C.; Rodríguez, N. Angew. Chem., Int. Ed. 2008, 47, 3043.

(d) Shang, R.; Fu, Y.; Li, J.-B.; Zhang, S.-L.; Guo, Q.-X.; Liu, L. J. Am. Chem. Soc. 2009, 131, 5738.

[25] Chen, R.; Zeng, L.; Huang, B.; Shen, Y.; Cui, S. Org. Lett. 2018, $20,3377$.

[26] Habert, L.; Retailleau, P.; Gillaizeau, I. Org. Biomol. Chem. 2018, 16,7351 .

[27] (a) Qin, T.; Cornella, J.; Li, C.; Malins, L. R.; Edwards, J. T.; Kawamura, S.; Maxwell, B. D.; Eastgate, M. D.; Baran, P. S. Science 2016, 352, 801 .

(b) Cornella, J.; Edwards, J. T.; Qin, T.; Kawamura, S.; Wang, J.; Pan, C. M.; Gianatassio, R.; Schmidt, M.; Eastgate, M. D.; Baran, P. S. J. Am. Chem. Soc. 2016, 138, 2174.

(c) Toriyama, F.; Cornella, J.; Wimmer, L.; Chen, T. G.; Dixon, D. D.; Creech, G.; Baran, P. S. J. Am. Chem. Soc. 2016, 138, 11132 (d) Qin, T.; Malins, L. R.; Edwards, J. T.; Merchant, R. R.; Novak, A. J. E.; Zhong, J. Z.; Mills, R. B.; Yan, M.; Yuan, C.; Eastgate, M. D.; Baran, P. S. Angew. Chem., Int. Ed. 2019, 58, 112.

(e) Qin, T.; Malins, L. R.; Edwards, J. T.; Merchant, R. R.; Novak, A. J. E.; Zhong, J. Z.; Mills, R. B.; Yan, M.; Yuan, C. X.; Eastgate, M. D.; Baran, P. S. Angew. Chem., Int. Ed. 2017, 56, 260.

(f) Edwards, J. T.; Merchant, R. R.; McClymont, K. S.; Knouse, K. W.; Qin, T.; Malins, L. R.; Vokits, B.; Shaw, S. A.; Bao, D. H.; Wei, F. L.; Zhou, T.; Eastgate, M. D.; Baran, P. S. Nature 2017, 545, 213.

[28] Huang, B.; Zeng, L.; Shen, Y.; Cui, S. Chem. Commun. 2017, 53, 11996.

[29] (a) Wasserman, H. H.; Wharton, P. S. J. Am. Chem. Soc. 1960, 82 , 661 .

(b) Wasserman, H. H.; Wharton, P. S. Tetrahedron 1958, 3, 321.

[30] Kita, Y.; Akai, S.; Yoshigi, M.; Nakajima, Y.; Yasuda, H.; Tamura, Y. Tetrahedron Lett. 1984, 25, 6027.

[31] Kita, Y.; Akai, S.; Ajimura, N.; Yoshigi, M.; Tsugoshi, T.; Yasuda, H.; Tamura, Y. J. Org. Chem. 1986, 51, 4150.

[32] Kita, Y.; Akai, S.; Yamamoto, M.; Taniguchi, M.; Tamura, Y. Synthesis 1989, 334. 
[33] Yin, J.; Bai, Y. H.; Mao, M. Y.; Zhu, G. G. J. Org. Chem. 2014, 79, 9179.

[34] Zeng, L.; Huang, B.; Shen, Y.; Cui, S. Org. Lett. 2018, 20, 3460.

[35] (a) Zeng, L.; Lai, Z.; Cui, S. J. Org. Chem. 2018, 83, 14834. (b) Zeng, L.; Sajiki, H.; Cui, S. Org. Lett. 2019, 21, 6423.

[36] Berger, D.; Neuenschwander, M. Helv. Chim. Acta 1996, 79, 192.

[37] Mishiro, K.; Yushima, Y.; Kunishima, M. J. Org. Chem. 2018, 83, 13595.

[38] (a) Wang, H.; Cheng, Y.; Becker, P.; Raabe, G.; Bolm, C. Angew. Chem., Int. Ed. 2016, 55, 12655.

(b) Priebbenow, D. L.; Becker, P.; Bolm, C. Org. Lett. 2013, 15, 6155.

[39] Pirwerdjan, R.; Becker, P.; Bolm, C. Org. Lett. 2015, 17, 5008.

[40] (a) Kossler, D.; Perrin, F. G.; Suleymanov, A. A.; Kiefer, G.; Scopelliti, R.; Severin, K.; Cramer, N. Angew. Chem., Int. Ed. 2017, 56,
11490.

(b) Jeanbourquin, L. N.; Scopelliti, R.; Tirani, F. F.; Severin, K. Org. Lett. 2017, 19, 2070.

(c) Suleymanov, A. A.; Scopelliti, R.; Tirani, F. F.; Severin, K. Adv. Synth. Catal. 2018, 360, 4178.

(d) Tan, J. F.; Bormann, C. T.; Perrin, F. G.; Chadwick, F. M.; Seyerin, K.; Cramer, N. J. Am. Chem. Soc. 2019, 141, 10372.

[41] Perrin, F. G.; Kiefer, G.; Jeanbourquin, L.; Racine, S.; Perrotta, D.; Waser, J.; Scopelliti, R.; Severin, K. Angew. Chem., Int. Ed. 2015, $54,13393$.

[42] Landman, I. R.; Acuna-Bolomey, E.; Scopelliti, R.; Fadaei-Tirani, F.; Seyerin, K. Org. Lett. 2019, 21, 6408.

[43] Zeng, L.; Chen, R.; Zhang, C.; Xie, H.; Cui, S. Chem. Commun. 2020, 56, 3093.

(Cheng, F.) 